NBER WORKING PAPER SERIES

\title{
DURABLE CONSUMPTION AND ASSET MANAGEMENT WITH TRANSACTION AND OBSERVATION COSTS
}

\author{
Fernando E. Alvarez \\ Luigi Guiso \\ Francesco Lippi \\ Working Paper 15835 \\ http://www.nber.org/papers/w15835
}

\author{
NATIONAL BUREAU OF ECONOMIC RESEARCH \\ 1050 Massachusetts Avenue \\ Cambridge, MA 02138 \\ March 2010
}

We thank Pierpaolo Benigno, Tullio Jappelli, Igor Livshits, Bob Lucas, Giuseppe Moscarini, Luigi Paciello, Stavros Panageas, Nicola Pavoni, Rob Shimer, Gianluca Violante, and seminar participants at the Banque de France, the University of Chicago, EIEF, London School of Economics, Berkeley, Yale, MIT and the Vienna Macro Conference 2009 for comments. Alvarez and Lippi thank the Banque de France for nancial support. Guiso thanks Unicredit for granting access to their households surveys. The views expressed herein are those of the authors and do not necessarily reflect the views of the National Bureau of Economic Research.

NBER working papers are circulated for discussion and comment purposes. They have not been peerreviewed or been subject to the review by the NBER Board of Directors that accompanies official NBER publications.

(C) 2010 by Fernando E. Alvarez, Luigi Guiso, and Francesco Lippi. All rights reserved. Short sections of text, not to exceed two paragraphs, may be quoted without explicit permission provided that full credit, including $\odot$ notice, is given to the source. 
Durable consumption and asset management with transaction and observation costs Fernando E. Alvarez, Luigi Guiso, and Francesco Lippi

NBER Working Paper No. 15835

March 2010

JEL No. E2,E21,G11

\begin{abstract}
$\underline{\text { ABSTRACT }}$
The empirical evidence on rational inattention lags far behind the theoretical developments: micro evidence on the most immediate consequence of observation costs the infrequent observation of state variables is not available in standard datasets. We contribute to lling the gap with two novel household surveys that record the frequency with which investors observe the value of their nancial investments, as well as the frequency with which they trade in nancial assets and durable goods. We use these data to test some predictions of existing models and show that to match the patterns in the data we need to modify these models by shifting the focus from non-durable to durable consumption. The model we develop features both observation and transaction costs and implies a mixture of time-dependent and state-dependent rules, where the importance of each rule depends on the ratio of the observation to the transaction cost. Numerical simulations show that the model can produce frequency of portfolio observations and asset trading comparable to that of the median investor (about 4 and 0.4 per year, respectively) with small observation costs (about 1 basis point of nancial wealth) and larger transaction costs (about 30 basis points of nancial wealth). In spite of its small size the observation cost gives rise to infrequent information gathering (between monthly and quarterly). A quantitative assessment of the relevance of the observation costs shows that the behavior of investors is essentially unchanged compared to the one produced by a model with transaction but no observation cost. We test a novel prediction of the model on the relationship between assets trades and durable-goods trades and nd that it is aligned with the data.
\end{abstract}

Fernando E. Alvarez

University of Chicago

Department of Economics

1126 East 59th Street

Chicago, IL 60637

and NBER

f-alvarez1@uchicago.edu

Luigi Guiso

European University Institute

Economics Department

Villa San Paolo

50133 Florence

ITALY

luigi.guiso@eui.eu
Francesco Lippi

University of Sassari

Department of Economics

and

Ente Einaudi, via Due Macelli, 73

00184 Rome - Italy

flippi@uniss.it 


\section{Introduction}

A large literature documents that several economic decisions occur infrequently. ${ }^{1}$ For instance, individual investors adjust their portfolios sporadically even though the prices of many assets experience large fluctuations at high frequency. Similarly, firms do not reset the price every time their input costs change. These infrequent adjustments at the micro level are a potential source of sluggish behavior at the aggregate level and have thus attracted the interest of macroeconomists. One hypothesis that has received attention in the recent literature is that inaction might result from the presence of observation costs, i.e. costs related to the information gathering process, such as those due to the monitoring of the value of equity (in the case of a consumer/ investor) or the monitoring of production costs (in the case of a firm). The optimality of economizing attention when information gathering is costly is what we refer to as the "rational inattention" hypothesis. ${ }^{2}$

Besides the intuitive appeal of observation costs, an important methodological reason that makes it interesting is that the nature of the optimal adjustments implied by this friction is different from the one generated by standard fixed cost, and this translates into different implications for aggregate behavior. Duffie and Sun (1990), Gabaix and Laibson (2001), Abel, Eberly, and Panageas (2007) show that with observation costs the optimal rule implies time-dependent adjustments, as opposed to state-dependent adjustments that are typical in the standard fixed-cost literature. Abel, Eberly, and Panageas (2009) show that a time-dependent rule may be optimal even in an environment with both observation and transactions costs. Understanding the nature of the decision rule matters because the aggregation of agents following time-dependent rules is different from the one of agents following state-dependent rules as argued by Gabaix and Laibson (2001) and Alvarez, Atkeson, and Edmond (2003) in the consumption-savings and price-setting literature, respectively. Finally, the modeling of inattentive investors, whose active participation in markets is only sporadic, may be important to understand the dynamics of assets prices, as argued by Duffie (2010).

In spite of the theoretical developments that rational inattention has inspired, micro evidence on rational inattention lags behind. Empirical evidence on the most immediate consequence of observation costs - the infrequent observation of state variables - is not available in standard datasets. We contribute to filling the gap with two novel household surveys that record the frequency with which individuals observe the value of their financial

\footnotetext{
${ }^{1}$ See Stokey (2008) for a survey of the recent literature.

${ }^{2}$ Two broad areas where this hypothesis is studied are the consumption, savings, and portfolio theory (see e.g. Duffie and Sun (1990), Gabaix and Laibson (2001), Sims (2003) and Reis (2006a), Abel, Eberly, and Panageas (2007) and price setting problems (see e.g. Mankiw and Reis (2002) and Woodford (2008)). Our use of the term "rational inatenttion" is broader than as seminally proposed by Sims, and follows more closely the use by Reis and Abel et all.
} 
investments, as well as the frequency with which they trade assets and durable goods. We use these data to test key predictions of existing rational inattention models and to quantify the relative importance of the observation cost relative to standard transactions costs. We find that to match important patterns in the data and to distinguish between between both types of cost we need to introduce a new model that shifts the focus from non-durable to durable consumption. The model we develop implies a mixture of time-dependent and statedependent rules, where the importance of each rule depends on the relative magnitude of the observation and transaction costs.

Our starting point are the models developed by Duffie and Sun (1990), Gabaix and Laibson (2001), Reis (2006a), and Abel, Eberly, and Panageas (2007, 2009). These seminal contributions explore the consequences of observation costs in the context of a household optimal savings problem that includes the optimal management of a low return liquid asset, required to pay for transactions, analogous to the monetary models with a cash in advance constraint. Section 2 reviews these models and their predictions for the patterns of nondurable consumption, trade in financial assets (purchase or liquidation of assets), information collection about the financial portfolio and liquid asset holdings.

In Section 3 we introduce two original datasets that are tailor-made to provide detailed evidence on these patterns. We find a robust pattern consistent with the assumption that an important component of adjustment costs is information gathering, namely that the frequency of trading, the frequency of observation and the time spent collecting financial information are strongly correlated across investors. However, we find no evidence supporting two important mechanisms operating in these models. In particular, the models of Duffie and Sun (1990), Gabaix and Laibson (2001), and Abel, Eberly, and Panageas (2007, 2009) predict that the observed frequency of observation and financial transactions should coincide, and also predict that the household liquidity (e.g. the average M1 or M2 balances) should decrease with the frequency of trades in assets. Our analysis shows that both predictions are poorly born out in the data: the frequency of information acquisition is at least 3 times larger than the frequency of portfolio trades. Moreover, the data shows little or no evidence of a negative link between the household liquidity and the frequency of asset trades.

In Section 4 we develop a new model that overcomes these two empirical shortcomings while preserving a central role for the cost of observation. We depart from the previous literature by focusing on durable, as opposed to non-durable, consumption goods. This shift has two important consequences. First in the model with durable consumption the agent optimally chooses to hold no liquid asset just until the day of the purchase, even if transactions are subject to be paid using a liquid asset. This is because durable goods purchases are infrequent and can thus be made so as to coincide with assets trades. Hence 
the average holdings of liquid assets is unrelated to the frequency of assets trades, consistent with the patterns observed in the data. ${ }^{3}$ Second, in the model with durable consumption with both observation and transactions costs, the observation frequency is larger than the trading frequency, as in the data. The reason for this result is that durable goods and transactions costs give rise to an inaction region, just like in Grossman and Laroque (1990) and Stokey (2009), where the agent tolerates moderate deviations of the durable goods stock from the frictionless benchmark. Thus, every time the agent observes her wealth and finds it to be in the inaction region the model produces an observation without a trade.

In Section 5 we use numerical simulations of the model to gauge the order of magnitude of observation and transactions costs that are consistent with observed investors' behavior. This exercise shows that very small observation costs are sufficient to reproduce the frequency of observation that is found in the data. Section 6 tests two novel predictions of the durable good model. First, that the frequencies of assets transactions and that of durable adjustment should be related. Second, that since more risk tolerant individuals invest more in volatile assets, they value information more and thus observe more frequently. The data lend support to both predictions.

Section 7 concludes with a discussion of our quantitative findings, and a comparison with the findings in Alvarez, Lippi, and Paciello (2009) on firms' price setting behavior in a model with observation and menu costs. We also discuss the role of labor income, an ingredient that is absent in the literature on which we build this paper, the possibility that some portfolio observations are available at no cost, and other issues for future research.

\section{Inattention, Liquidity and Non-Durable Goods}

This section reviews a class of models that use the rational inattention hypothesis to study consumption, savings, portfolio theory and liquidity. In these models the relevant decisions concern the rate of consumption - or savings - and the portfolio composition; the costs are those associated with keeping track of the information about financial variables. Examples of these models are Duffie and Sun (1990), Gabaix and Laibson (2001), Sims (2005), Reis (2006a), Abel, Eberly, and Panageas (2007, 2009) among others.

We describe a version of the rational inattention model of Abel, Eberly, and Panageas (2009). Households maximize discounted expected utility derived from the consumption of non-durables $c$ and period utility $u(c)=c^{1-\gamma} /(1-\gamma)$, with CRRA coefficient $\gamma$, and discount

\footnotetext{
${ }^{3} \mathrm{An}$ example is the purchase of a house, which occurs infrequently and is typically paid for with the proceeds of a sale of a financial asset executed immediately before the house purchase, as opposed to being paid with balances accumulated in a transaction account with a low yield. Once the date of purchase is decided, it is optimal to liquidate the high-yield investments in the proximity of the house purchase.
} 
rate $\rho$. The purchases of non-durable goods are subject to a cash-in-advance constraint (CIA): agents must pay with resources drawn form a liquid asset account, with real value denoted by $m$. Non-negative liquid assets represent a broad monetary aggregate, such as M2, and have a low real return $r_{L}$. The agent's source for the liquid asset is her financial wealth $a$, a fraction $\alpha$ of which is invested in risky assets and the remaining in risk-less bonds. The risk-less bond yields $r>r_{L}$, and the risky asset has continuously compounded normally distributed return, with instantaneous mean $\mu$ and variance $\sigma^{2}$ (the portfolio is assumed to be managed so that it stays continuously rebalanced with fraction $\alpha$ of risky asset). There is a fixed cost $\phi_{o}$ of observing the value of the agent's financial wealth and a fixed cost $\phi_{T}$ of changing $\alpha$ and transferring resources between the investment and the liquid assets accounts. From now on we call observation the agent's act of observing the value of the her financial wealth, and trade the agent's act of adjusting the portfolio. We assume that the costs are fixed, in the sense that they are incurred regardless of the size of the adjustment, but they are proportional to the current value of the stock variable $a$. This specification, which is standard in the literature - see for example Grossman and Laroque (1990) and Abel, Eberly, and Panageas (2007) - is adopted for convenience, since it preserves the homogeneity of the value function, and hence reduces the dimensionality of the problem. We remark that the models of Duffie and Sun (1990), Gabaix and Laibson (2001), Abel, Eberly, and Panageas (2007) are obtained as a special case of this model by setting the trade cost $\phi_{T}=0$.

We denote by $V(a, m)$ the value of the problem for an agent with current liquid assets $m$, who has just paid the observation cost discovering that her financial wealth is $a$. She must decide whether to pay the cost $\phi_{T}$, choose $\alpha$ and transfer some resources to/from the liquid account, as well as $\tau$, the length of the time period until the new observation of her financial assets. The budget constraint at the time of observation is

$$
a^{\prime}+m^{\prime}+a \phi_{T} I_{m^{\prime} \neq m}=a+m
$$

where $I_{\{\cdot\}}$ is an indicator of transfers. Letting $N(s)$ be the CDF of a standard normal, and $R(s, \tau, \alpha)$ be the gross return during $\tau$ period with portfolio $\alpha$ when the innovation to the returns is $s$, we have:

$$
R(s, \tau, \alpha) \equiv e^{\left(\alpha \mu+(1-\alpha) r-\frac{\alpha^{2} \sigma^{2}}{2}\right) \tau+\alpha \sigma s \sqrt{\tau}} .
$$

This is the gross return to a portfolio that is continuously rebalanced to have fraction $\alpha$ in the risky asset with instantaneous return with mean $\mu$ and variance $\sigma^{2}$ per unit of time, i.e.

$$
\frac{1}{\tau} \mathbb{E}[R(s, \tau, \alpha)-1] \rightarrow \alpha \mu+(1-\alpha) r \quad, \quad \frac{1}{\tau} \operatorname{Var}[R(s, \tau, \alpha)-1] \rightarrow \alpha^{2} \sigma^{2} .
$$


Then the value function solves:

$$
V(a, m)=\max _{m^{\prime}, \alpha, \tau, c(\cdot)} \int_{0}^{\tau} e^{-\rho t} u(c(t)) d t+e^{-\rho \tau} \int_{-\infty}^{\infty} V\left(a^{\prime}\left(1-\phi_{o}\right) R(s, \tau, \alpha), m(\tau)\right) d N(s)
$$

subject to the budget constraint (1) at the time of the adjustment, and to the liquid assetin-advance constraint between adjustment:

$$
\mathrm{d} m(t) / \mathrm{d} t=r_{L} m(t)-c(t), \quad m(0)=m^{\prime}, \quad m(t) \geq 0, \quad \text { for } t \in[0, \tau] .
$$

An interesting result common to the models of Duffie and Sun (1990), Gabaix and Laibson (2001), and Abel, Eberly, and Panageas (2007, 2009) is that trades and observations coincide. In particular, consider an agent with $m=0$, so at this time she must observe and trade. Then she would choose a transfer $m^{\prime}(0)>0$ from her financial asset to her liquid asset, a future observation date $\bar{\tau}$, a portfolio share $\alpha$, and path of consumption between adjustments $c(\cdot)$, with the property that $m(\bar{\tau})=0$, i.e. she is planning to run out of liquid asset just at the next observation date. In other words, starting from a state of zero liquid asset, the agent will observe at deterministic equally spaced intervals of length $\bar{\tau}$, and every time she observes the value of her financial assets she will transfer resources to her liquid account.

Figure 1: Simulated Path of Financial Asset $a(t)$ and Liquid Assets $m(t)$

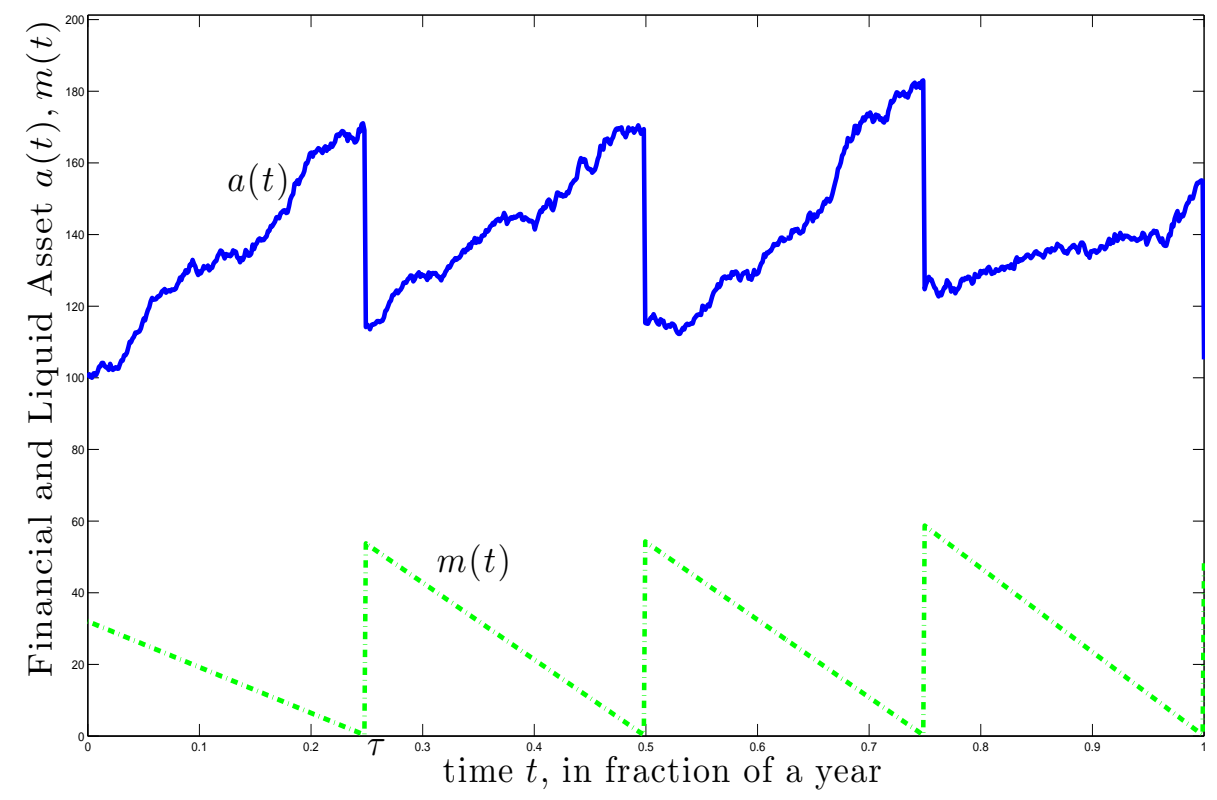

The nature of the optimal policy is illustrated in Figure 1, which displays the values 
for the financial asset and liquid asset in a simulation for an agent following the optimal policy. Notice that the liquid asset $m(t)$ follows a saw-tooth path familiar from the inventory models, such as Baumol-Tobin's classic problem, with withdrawals (and observations) at equally spaced time periods: $0, \bar{\tau}, 2 \bar{\tau}$, etc. One difference compared to Baumol and Tobin is that the value of the withdrawal (the vertical jumps up in $m(t)$, and down for $a(t)$ in Figure 1), and hence the rate of consumption between successive withdrawals, depends on the level of the financial assets that the agent observes just before the withdrawal. ${ }^{4}$ We stress that in this model following the optimal policy implies that every observation coincides with a trade. Also notice, for future reference, that the homogeneity of the problem implies that after an observation and trade, the agent sets the same ratio $m(0) / a(0) \equiv \bar{m}$.

The saw-tooth pattern of liquid asset holdings displayed in the figure makes clear that the model predicts a negative correlation between the average liquidity (scaled by non durable consumption) and the number of transactions (e.g. liquidity transfers), as in the standard inventory model of cash holdings. ${ }^{5}$ For instance, in the Baumol-Tobin deterministic model the average liquid balance equals half of the liquidity transfer. Together with the identity positing that the product of the number of transactions $(n)$ times the average liquidity transfer $(2 \mathrm{~m})$ is equal to the flow of expenditure over a given time period $(c)$, gives us $M / c=1 /(2 n)$. This implies that the $\log$ correlation between $M / c$ and the frequency of transactions is -1 . This same prediction holds in this model and can be tested empirically, as we do in Section 3.4. ${ }^{6}$

Interestingly Abel, Eberly, and Panageas (2009) show that the synchronization between observation and trading holds not only when the cost of transferring resources from financial asset to liquid asset is zero, i.e. when $\phi_{T}=0$, but also for $\phi_{T}>0$, provided that this cost is not too large. For the case when $\phi_{T}>0$ this is a surprising result. To see that, notice that it implies that the following deviation is not optimal. Increase the amount of liquid asset withdrawn $m(0)$, keep the same consumption profile, pay the observation cost, and learn the value of the financial assets at the scheduled time $\bar{\tau}$. Note that by construction in the deviation $m(\bar{\tau})>0$. At this time consider following a $s S$ type policy: if the ratio $m(\bar{\tau}) / a(\bar{\tau})$ is similar to what it would have been after a withdrawal (given by $\bar{m}$ ), then do not trade. If the ratio is small enough, then pay the trade cost $\phi_{T}$, trade, and set the ratio $m(0) / a(0)$ equal to $\bar{m}$. This deviation has the advantage of saving the fixed trading cost $\phi_{T}$ with a strictly positive probability (i.e. the probability that $m(\bar{\tau}) / a(\bar{\tau})$ is large). It has the disadvantage

\footnotetext{
${ }^{4}$ In the example considered in the figure, following the model parametrization by Abel, Eberly, and Panageas (2009), the time variation in the size of withdrawals is small because the variance of the portfolio return is small relative to its mean trend.

${ }^{5}$ Unlike the classic currency management problem in Baumol and Tobin, the new models seem more appropriately applied to broader notions of liquidity, such as M1 or M2.

${ }^{6}$ Alvarez and Lippi (2009) show that the negative correlation between $m / c$ and $n$ extends to stochastic inventory models.
} 
that it increases the opportunity cost by holding more of the liquid asset. Abel, Eberly, and Panageas (2009) show that indeed this deviation is not optimal, provided that $\phi_{T}$ is not too large. We will return to this when we present our model based on durable goods.

\section{Observations, Trades, and Liquidity: Theory vs. Data}

The model in the previous section carries very neat implications on at least two potentially observable - and thus testable - behaviors: first, since investors do their best to avoid collecting information when it is not needed, they should keep the frequency of observations as close as they can to the frequency of financial trades. In Duffie and Sun (1990), Gabaix and Laibson (2001), Abel, Eberly, and Panageas (2007, 2009) as well as in our version of their model, the two actually coincide, providing a very strong empirical prediction. Second, because the combination of a cash in advance constraint and the use of money (only) to purchase non-durable goods gives rise to a Baumol-Tobin-type management of liquid assets, investors that trade more frequently should have lower average holdings of liquid assets. In this section we bring these predictions to bear with a novel set of data that contains information on how frequently people choose to observe the value of their financial assets and trade them as well as data on the value and composition of their liquid and financial assets.

\subsection{Data sources}

Our empirical evidence relies on two different sources. The first is the Unicredit Survey (UCS), which gathers information on a sample of about 1,800 Italian investors with an account at Unicredit, one of the largest banking groups in Europe. We base most of the analysis on the first wave, run in 2003 but occasionally we also rely on data from the 2007 wave. The novel and original feature of this survey is the wealth of information that it has on the frequency people gather information on their financial investments and make financial transactions as well as on investors' risk preferences, assets and demographics which provide an ideal setting for testing predictions of models that emphasize information and transaction costs in household savings and financial decisions. We complement the UCS survey with the 2004 Survey of Households Income and Wealth - a widely used survey on a sample of about 8,000 Italian households managed by the Bank of Italy. This dataset has two useful features: first, unlike UCS it collects detailed data on durable purchases; this particular wave has also information on the frequency investors make financial trades. Both will prove important in Section 6 to test the predictions of the model we develop in Section 4. Second, while UCS is representative of the population of Unicredit customers it is not of the Italian population; but 
SHIW is, and this allows us to make sure that our findings with UCS are not the reflection of sample selection.

\subsection{Key variables description}

To avoid cluttering the paper, we provide details about the two surveys and the variables that we use in the data appendix. Here we describe in some detail two key variables for our analysis: the frequency investors observe investments and the frequency they trade financial assets.

To our knowledge, UCS is the first large scale survey to collect information on how frequently people check their financial investments and make financial trades. In the 2003 wave sample participants where asked: "How often do you check the value of your financial investments?". They could answer: a) every day; b) at least once a weak; c) every 15 days; d) once a month; e) about every three months; f) about every six months; g) about once in a year; h) less than once a year i) never check; l) have no investments. To obtain information on the frequency of financial trades they were asked: "How often do you change the composition of your financial portfolio and sell or buy financial assets?" The options are: a) every day; b) at least once a week; c) about every two weeks; d) about every month; e) about every three months; f) about every six months; g) about every year; h) less than once a year; i) at maturity; l) never; m) I have no investments.

Similar questions were asked in the 2007 UCS wave while the trade frequency question, with the same wording, was also asked in the 2004 SHIW. The only difference with respect to the UCS question is that the first two answers are lumped together as "at least once a weak". Obviously, questions only apply to active investors, implying that some observations (316 in UCS 2003 out of 1,834 participants) will be lost. Next, we use these data to confront two predictions of the rational inattention model discussed in Section 2.

\subsection{Prediction \#1: portfolio observations and trades coincide}

Table 1 shows the joint distribution of the frequency of observing and that of asset trading among the 2003 UCS investors. The table documents several noteworthy features. First, the large mass of observations on the main diagonal of the table shows that there is a strong positive correlation between the frequency with which agents observe their investments and the frequency of asset trading: those who observe the portfolio more often also tend to trade more often. Second, in only a handful of cases (6 percent of the observations) investors trade more frequently than they observe. These two features are implied by the important notion, embedded in the model in Section 2, that investors economize on information gathering costs 
Table 1: Frequencies of portfolio observation and trade in UCS 2003

\begin{tabular}{c|cccccccccc}
\hline \hline & \multicolumn{10}{|c}{ Observations per year: } \\
& 365 & 52 & 26 & 12 & 4 & 2 & 1 & $<1$ & - & never \\
\hline Trades per year: & & & & & & & & & \\
365 & $\mathbf{2 9}$ & 5 & 1 & 1 & 0 & 0 & 0 & 0 & 0 \\
52 & 14 & $\mathbf{2 4}$ & 2 & 4 & 2 & 0 & 1 & 0 & 0 \\
26 & 13 & 18 & $\mathbf{1 3}$ & 7 & 1 & 0 & 0 & 0 & 0 \\
12 & 16 & 29 & 35 & $\mathbf{6 5}$ & 17 & 3 & 1 & 3 & 0 \\
4 & 18 & 19 & 24 & 97 & $\mathbf{1 0 3}$ & 6 & 2 & 0 & 2 \\
2 & 5 & 20 & 23 & 63 & 84 & $\mathbf{5 3}$ & 2 & 0 & 2 \\
1 & 9 & 14 & 8 & 37 & 48 & 33 & $\mathbf{1 6}$ & 1 & 4 \\
$<1$ & 7 & 17 & 12 & 37 & 41 & 29 & 7 & $\mathbf{2 4}$ & 8 \\
at maturity & 11 & 17 & 5 & 48 & 60 & 23 & 27 & 38 & - & 13 \\
never & 4 & 4 & 0 & 9 & 15 & 14 & 4 & 12 & $\mathbf{3 5}$ \\
\hline \hline
\end{tabular}

Source: Unicredit survey 2003, All investors. Each entry is the number of household observation in each cell; Entries on main diagonal highlighted in bold. Summary stats: Fraction on main diagonal: 24\%; Fraction below main diagonal: $70 \%$.

and lend support to some of the mechanisms captured by Duffie and Sun (1990), Gabaix and Laibson (2001), Abel, Eberly, and Panageas (2007, 2009) theories. The fact that few investors trade more often than they observe may be due to minor measurement errors (reassuring about the quality of our indicators of observing and trading frequencies) or reflect rare cases where investors trade blindly.

Table 2 reports summary statistics on the frequency of observing and trading for different groups of investors both from the UCS 2003 and the SHIW 2004 surveys. Consistently with models that stress information gathering costs and assets trading costs, investors observe their investments and trade assets infrequently. The median number of portfolio observations per year in the sample of UCS investors (direct and indirect) is 12, while the median number of asset trades is 2. Smaller frequencies for asset trading are estimated for the investors in the SHIW (in the lower panel of the Table). The SHIW statistics, computed on a sample that is representative of the Italian investors, are similar to those observed for US households. For instance Bonaparte and Cooper (2009), using the Survey of Consumer Finances, report that the fraction of household owning stocks that adjust their portfolio in one year is 0.7 , the same value that appears for the median stockholder in the SHIW (which corresponds to one trade every 1.4 years). ${ }^{7}$ The table also reports an estimate for the median number of observations

\footnotetext{
${ }^{7}$ ICI (2005b) reports information on US equity investors. Figure 33 shows that for 1998, 2001 and 2004 the fraction of investors (who own equities) that have made no trades in equity during a year is $0.58,0.6$, and 0.6 respectively. Assuming a Poisson distributed number of trades with constant intensity this implies
} 
in the SHIW sample, imputed from a regression estimated on the UCS data (see the note to the table for more details). The frequency of observation for the equity investor in the SHIW sample is about $1 / 2$ that for the UCS sample of equity investors.

Table 2: Number of portfolio observations and trades per year

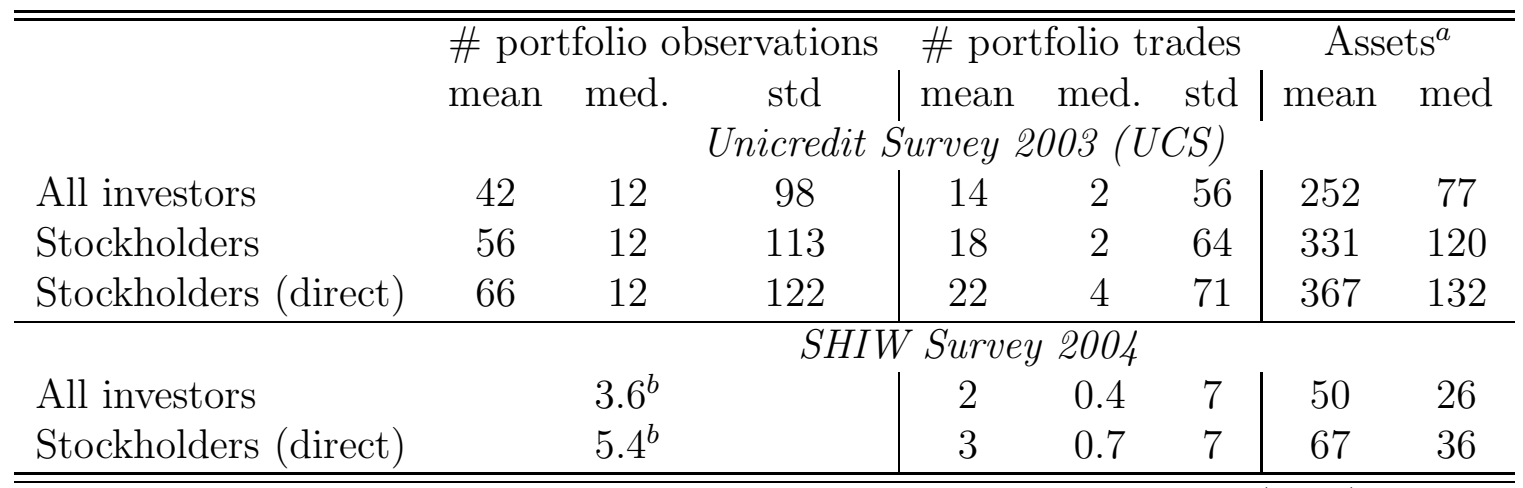

Note: The upper panel is based on the Unicredit survey for 2003. All investors (1,518) are individuals with at least 1,000 euros in bank deposits who also have some other financial investments. This survey is designed to oversample the wealthy. Stockholders (984) includes individuals holding stocks of listed or unlisted firms directly, or through a mutual fund, or a managed investment account. Direct stockholders (736) includes individuals holding stocks of listed or unlisted companies directly. The lower panel is based on SHIW 2004 survey, that is designed to be representative of Italian households. It includes 2,808 households with financial assets other than bank or postal account (1,535 of which own stocks directly). See Appendix A for a more detailed description and comparison of these surveys. $-{ }^{a}$ Thousands, in 2003 euros. $-{ }^{b}$ Imputed to the SHIW investors from a regression estimated on the UCS data. The specification (in logs) includes the following regressors: the number of asset trades, the investor's financial assets and controls for the investor age, gender, education and marital status. The $R^{2}$ is 0.3 for the UCS full sample and 0.2 for the UCS sample of stockholders. In each SHIW sample the reported quantity is the median of the fitted values produced by the estimated regression.

Though this evidence is consistent with the costly observation hypothesis it also departs from it in one important dimension. Contrary to Duffie and Sun (1990), Gabaix and Laibson (2001), Abel, Eberly, and Panageas (2007, 2009), the data show that investors do not trade every time they observe the value of their investments. Instead, they observe their investments more often than they trade. The frequency of trading and the frequency of observation coincide for only $28 \%$ of the investors (those along the diagonal in Table 1 ); for $67 \%$ of the investors the observation frequency is higher than the trading frequency. Thus, only a minority of the investors in the sample conforms to the strong prediction of the model in Section 2. Table 2 confirms that investors observe the value of their investments more frequently than they trade, with a ratio between the two average frequencies around 3 . This pattern holds across investors type, asset levels, and trade-frequency.

an average of about 0.51 trades per year. 
We stress that these patterns are unlikely to be the reflection of poor measurement (e.g. of the frequency investors observe their investments) or of some particular feature of the survey wave. To address the first concern, we rely on an independent measure available in the 2003 UCS of the amount of financial information investors collect from various sources (such as newspapers, the web, their advisors or the companies' accounting statements) before making an investment decision. This is a broad measure of the time investors devote to gathering financial information. One would expect that investors who collect more financial information in general, also observe the value of their investments more frequently, and this is indeed the case as shown in Figure A-8 in Appendix A. Measurement errors could be present in the frequency of trades. However the ones that may conceivably affect our measure are, if anything, working to make the positive gap between observing and trading frequency measured in UCS an underestimate of the theoretically relevant one. In the model trading means transferring resources from a savings to a liquid account; in the data, given the wording of the question, some of the trades may involve portfolio re-balancing with no transfers to or from the liquid account. While we do not have information for Italy about the two type of trades, survey data on US investors report that in more than $2 / 3$ of times the proceeds from sales of stocks by households are fully reinvested. ${ }^{8}$ Taking this into account would increase the estimated difference between the frequency of observing the value of investment and the frequency of trade involving transfers, i.e. would make the prediction of the simple version of the model of Section 2 even more counterfactual. To address the second concern, we have reproduced Table 1 using the 2007 UCS. The new joint distribution (not reported) has the same features as the one based on the 2003 wave: only $3.5 \%$ of the investors trade more frequently than they observe their investments; $24 \%$ equally frequently and $72.5 \%$ less frequently while the average number of observations stays in a ratio of 3 to 1 to the number of trades.

In sum, the joint empirical pattern of the frequency of observing one's investments and that of trading suggests that while the models of Duffie and Sun (1990), Gabaix and Laibson (2001), Abel, Eberly, and Panageas (2007, 2009) capture important features of this pattern, they fail to predict the systematic tendency of observing frequency to exceed that of trading frequency - a feature of the data that is unlikely to result from mis-measurement of these key variables.

\footnotetext{
${ }^{8}$ See Figure F.7 "Disposition of Proceeds from most recent sale of individual stocks", in ICI (2005a).
} 


\subsection{Prediction \#2: investors who trade more hold less liquidity}

If portfolio trades are mostly aimed at transferring resources from the asset account to the liquid account then those agents who trade more frequently should, on average, hold less liquid assets. Indeed, the model in Section 2 has an even stronger implication as it predicts a unitary elasticity between liquid assets holdings (scaled by non durable consumption) and the number of financial trades.

Figure 2: Household Liquidity vs. asset trade frequency

A. SHIW 2004

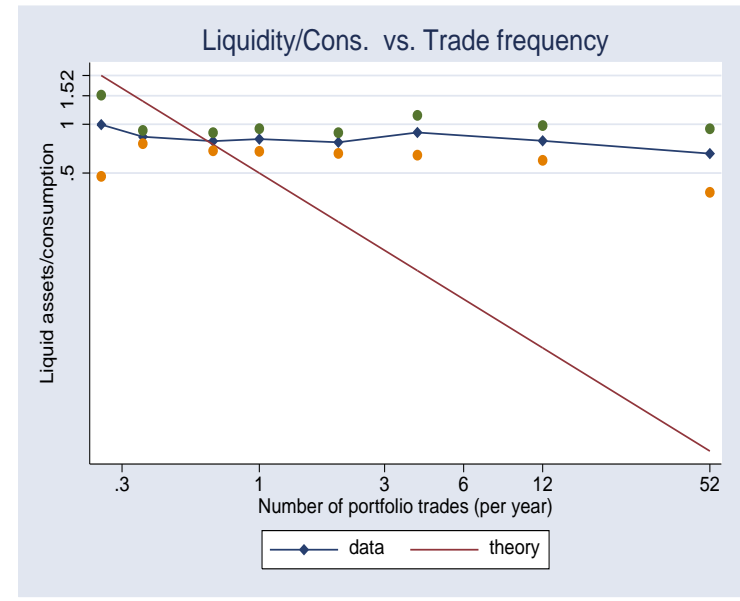

B. Unicredit 2003

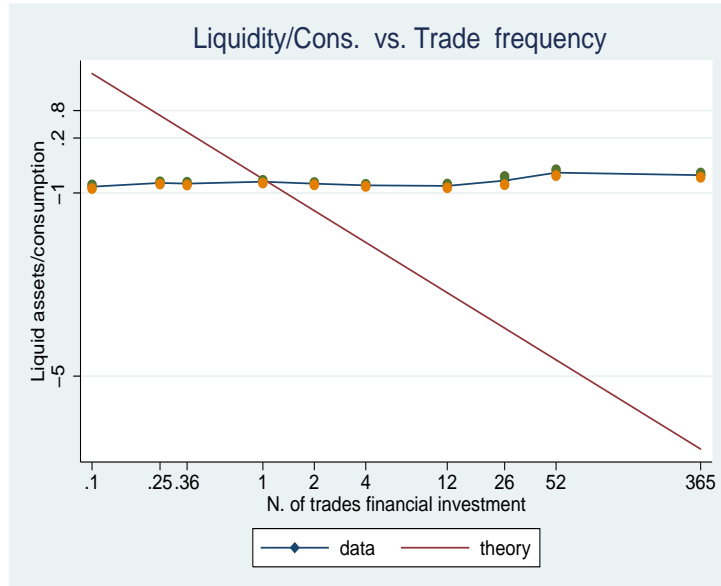

Note: $\log$ scale. Liquidity is measured by the ratio $M / c$, where $M$ is $M 2$ (similar results obtained for $M 1$ ) and $c$ is non-durable consumption (same results if total consumption is used); in the Unicredit survey consumption is imputed from a regression in the SHIW data using income and other demographics. For each trade frequency bin, the figure plots the mean of $M / c$ (dots denote the standard deviation of the mean statistic) and the model predicted relation, given by $M / c=$ $1 /(2 \cdot$ trading freq. $)$.

We test this prediction using both UCS data and SHIW data. Liquid assets are defined as the sum of cash holdings, checking and savings accounts - a measure close to M2 - but results are unaffected if we use a narrower definition that includes only cash and checking accounts. Since UCS collects no consumption data we impute it using the 2004 SHIW to estimate non-durable consumptions (see Appendix A for details). We then construct the ratio between liquid assets and consumption. Figure 2 plots both the empirical relation between the average level of liquid assets ratio in the sample and the number of trades and its theoretical counterpart as predicted by the model in Section 2. Panel A shows it using the SHIW data and Panel B using the UCS data. Contrary to the model prediction we find a very weak correlation between liquid assets holdings and number of trades. In both surveys the unconditional correlation is, if anything, slightly positive. This finding is quite robust as 
we discuss next.

Table 3 shows that the lack of correlation also emerges from multivariate regressions that condition on the cross-sectional variation in income, household size, age and the importance of labor income over total income. The reason for adding the latter variable is that one might be concerned that the match with the model is far from perfect, and that modeling labor income would change the results on the relation between the level of liquid asset and the frequency of transactions. As a preliminary control for this, we include the ratio of labor income to non-durable consumption in the regressions, and notice that the household liquidity remains uncorrelated, if anything slightly positively correlated, with the frequency of trades in assets (see footnote 11 for more details). Finally, similar results are obtained if wee use a broad measure of liquid assets instead of a narrow one, if we look at median liquid assets rather than means, if we scale liquid assets with total financial assets (in this case the simple correlation is somewhat negative both in the UCS sample and in the SHIW but the elasticity is far from the predicted unit value). ${ }^{9}$

Summing up, two predictions of the model in Section 2 - a one to one relation between the frequency of observing and that of trading financial assets and a one to one relation between (log) liquid assets and (log) number of trades - are poorly supported by the data. What makes this model inadequate? Not the information or transaction frictions, that are consistent with important features of the data such as the infrequent nature of observations and financial trades. Rather, we think that an important shortcoming of the model lies in its reliance on trades between financial assets and transaction accounts to derive a theory of liquid assets holdings to finance non-durable consumption. To further this view we contrast the prediction between the transactions frequency and demand for liquidity with the one, of identical nature, that emerges in the realm of currency demand models. We use information on average currency holdings and average number of cash withdrawals by Italian households taken from the SHIW survey. ${ }^{10}$ Table 4 reports the (log) correlation between the average currency balance and the frequency of transactions, measured by the number of cash withdrawals. The correlation is always negative and statistically different from zero (between -0.2 and -0.5). Despite the presence of large measurement error, as documented by Alvarez and Lippi (2009), the inventory theory of cash management finds strong support in the data, while the

\footnotetext{
${ }^{9}$ To further check whether the lack of correlation is due to the number of trades capturing some unobservable determinant of liquid assets holdings we regressed (unreported) the (log) liquid assets scaled by consumption (or total assets) on the (log) number of trades adding demographic controls, as well as controls for $(\log )$ consumption and assets. We have estimated this regression on several sub samples of investors: all investors, all stockholders, direct stockholders. In all cases we found a small elasticity of liquid asset to the number of financial trades, often positive (estimates in the UCS sample range between 0.02 and 0.10 depending on sample and specification) and always quite far from the negative one-to-one correspondence predicted by the model.

${ }^{10}$ See Attanasio, Guiso, and Jappelli (2002) and Alvarez and Lippi (2009) for a detailed analysis.
} 
Table 3: Liquidity (M2) vs. trade frequency (asset transactions)

Dependent variable: $(\log ) M / c$; Regressor: $(\log )$ asset trade frequency

\begin{tabular}{|c|c|c|c|c|}
\hline & \multicolumn{2}{|c|}{ Shiw data } & \multicolumn{2}{|c|}{ Unicredit data } \\
\hline & bivariate $^{a}$ & Multivariate $^{b}$ & bivariate $^{a}$ & Multivariate $^{b}$ \\
\hline All investors & \multicolumn{2}{|c|}{$(2,808$ obs. $)$} & \multicolumn{2}{|c|}{$(1,365$ obs. $)$} \\
\hline \multirow[t]{2}{*}{ Trade freq. (log) } & 0.005 & 0.03 & 0.10 & 0.13 \\
\hline & $(0.02)$ & $(0.02)$ & $(0.02)$ & $(0.02)$ \\
\hline Equity investors & \multicolumn{2}{|c|}{$(1,535$ obs. $)$} & \multicolumn{2}{|c|}{ (875 obs.) } \\
\hline \multirow[t]{2}{*}{ Trade freq. (log) } & 0.06 & 0.06 & 0.08 & 0.11 \\
\hline & $(0.03)$ & $(0.03)$ & $(0.03)$ & $(0.03)$ \\
\hline
\end{tabular}

Note: Based on the 2004 SHIW and 2003 Unicredit surveys. All regressions include a constant; standard errors in parenthesis. $M / c$ is the liquid asset to consumption ratio; $M$ is $M 2$ (similar results obtained for $M 1$ ); $c$ is non-durable consumption (same results if total consumption is used); for the Unicredit survey consumption is imputed from a regression in the SHIW data using income and other demographics. $-{ }^{a}$ Regression coefficient of bivariate OLS. $-{ }^{b}$ This regression includes the following controls (all in logs): household income, \% of labor income over non-durable consumption, age of household head, number of adults.

inventory theory for liquid assets management implicit in the model of Section 2 does not. In a nutshell: the data offer no evidence that asset transactions are used to finance non-durable consumption. ${ }^{11}$ In the next section we show how keeping the frictions but abandoning non durable consumption can reconcile theory and data.

\section{Inattention and Durable Goods}

This section presents a model to overcome the two empirical shortcomings discussed above, while preserving a central role for the cost of information acquisition. One novel element compared to the previous literature with costly observations is that the model focuses on durable, as opposed to non-durable, consumption. Additional empirical patterns consistent with our model are discussed in Section 6.

We consider the problem of a household who consumes only durable goods. She derives

\footnotetext{
${ }^{11}$ One may think that the omission of labor income that is credited directly into their liquid account, may be responsible for this empirical shortcoming of the model (just like direct cash transfers, e.g. wages paid in cash, might impinge on the Baumol-Tobin theory of the demand for currency). If this was the case, then controlling for the labor income should reveal a negative relation between average liquidity and the frequency of assets transactions. Instead, the lack of correlation between average liquidity and trades' frequency persists even in the multivariate regressions where the share of labor income over total non-durable consumption is controlled for (see Table 3).
} 
Table 4: Liquidity (Currency) vs. trade frequency (\# withdrawals)

\begin{tabular}{|c|c|c|c|c|}
\hline \multicolumn{5}{|c|}{ Dependent Variable $\log (M / c)$; Regressor: (log) withdrawal frequency $(n)$} \\
\hline & \multicolumn{2}{|c|}{ without ATM card } & \multicolumn{2}{|c|}{ with ATM card } \\
\hline & bivariate & multivariate & bivariate & multivariate \\
\hline $\log n$ & $-0.24^{* * *}$ & - & $-0.25^{* * *}$ & - \\
\hline $\log n$ & - & $-0.22^{* * *}$ & - & $-0.24^{* * *}$ \\
\hline & (900 obs.) & (900 obs.) & $(2,326$ obs. $)$ & (2,325 obs.) \\
\hline \multicolumn{5}{|c|}{ Dependent Variable $\log (W / c)$} \\
\hline & \multicolumn{2}{|c|}{ without ATM card } & \multicolumn{2}{|c|}{ with ATM card } \\
\hline & bivariate & multivariate & bivariate & multivariate \\
\hline $\log n$ & $-0.39^{* * *}$ & - & $-0.52^{* * *}$ & - \\
\hline \multirow[t]{2}{*}{$\log n$} & - & $-0.40^{* * *}$ & - & $-0.52^{* * *}$ \\
\hline & $(2,250$ obs.) & $(2,249$ obs. $)$ & (1,256 obs.) & (1,255 obs.) \\
\hline
\end{tabular}

The $\overline{\overline{a s t e r i s k s} \text { denote that the null hypothesis of a zero coefficient is rejected by a t-test with a } 1}$ per cent confidence level. $M=$ average currency holdings (coins and bills), $c=$ average consumption paid in cash during the year, $n=$ average number of cash withdrawals per year from ATM and bank-branches, $W=$ average size of withdrawal from ATM and bank branches. For the multivariate we include a dummy for self-employed, and the percentage of income paid in cash. Source: SHIW 2004.

utility proportional to the stock $d$ of durables, which depreciates at rate $\delta$. Her preferences are given by discounted expected utility, and a CRRA period utility $U(d)=d^{1-\gamma} /(1-\gamma)$. The agent's source of funds to buy/sell durables is her financial wealth $a$, a fraction $\alpha$ of which can be invested in risky securities and the remaining in risk-less bonds as in the previous section. As in Grossman and Laroque (1990), there is a fixed cost parameter $\phi_{T}$ of trading the durable goods. So, if there is an adjustment in the stock of durables, say from $d$ to $d^{\prime}$, and the concurrent financial trade, the agent looses $\phi_{T} d$. In addition, as in the rational inattention models of the previous section, there is also a fixed cost parameter $\phi_{o}$ of observing the value of the agent's financial wealth. For the same reasons as in the model with non-durable goods, i.e. to preserve homogeneity and conserve on the state space, the observation cost is assumed to be proportional to the asset value: $\phi_{o} a$.

Notice that we do not impose a cash in advance constraint for the durable expenditures (in terms of liquid assets). This is because, even if we imposed it, the lumpy nature of durable purchases would not contribute to the average holdings of liquid assets. In particular, the fixed cost gives rise to discrete adjustments, so that even when liquid assets are required to pay for the goods they will be withdrawn and spent immediately. In other words, the liquid asset used to pay for expenditures have an infinite velocity, hence they affect the 
average withdrawal size but have no effect on the average holdings of liquid assets. ${ }^{12}$ Hence in the durable goods model the frequency of financial trades and of durable purchases do not contribute to the average holdings of the household liquid assets. This is a desirable property of the model given the evidence of Section 3 of the lack of correlation between the household liquidity and the frequency of portfolio adjustment.

We let $V(a, d, \alpha)$ denote the value function for an agent who, after paying the observation cost, has a durable stock $d$, financial wealth $a$ with a fraction $\alpha$ invested in risky assets. She decides $\tau$, the length of time until the next observation date and whether to pay the cost $\phi_{T}$, transfer resources and adjust both the portfolio share $\alpha$ and her durables stock to $d^{\prime}$. These decisions are subject to the budget constraint:

$$
a^{\prime}+d^{\prime}+d \phi_{T} I_{\left(d^{\prime}, \alpha^{\prime}\right) \neq(d, \alpha)}=d+a
$$

where $I_{\{\cdot\}}$ is an indicator of adjustment (of the durable stock and portfolio share). The Bellman equation is then:

$$
\begin{aligned}
V(a, d, \alpha) & =\max _{a^{\prime}, d^{\prime}, \alpha^{\prime}, \tau} \int_{0}^{\tau} e^{-\rho t} U\left(d^{\prime} e^{-t \delta}\right) d t \\
& +e^{-\rho \tau} \int V\left(a^{\prime}\left(1-\phi_{o}\right) R\left(s, \tau, \alpha^{\prime}\right), d^{\prime} e^{-\delta \tau}, \alpha^{\prime}\right) d N(s)
\end{aligned}
$$

subject to the budget constraint (5), where $N(\cdot)$ is the CDF of a standard normal distribution, and $R(s, \tau, \alpha)$ is the gross return during a period of length $\tau$ of the portfolio with share $\alpha$ as defined in (2).

Since the portfolio and durable adjustment is subject to a fixed cost $\phi_{T}$, it is convenient to write the value function in (6) as:

$$
V(a, d, \alpha)=\max \{\bar{V}(a, d, \alpha), \hat{V}(a, d)\}
$$

The value function $V(a, d, \alpha)$ compares the value of two policies: $\bar{V}(a, d, \alpha)$, the value of observing wealth but not adjusting durable stocks, and $\hat{V}(a, d)$, the value of observing $a$ and adjusting durables as well as the portfolio share. Thus, $\bar{V}(a, d, \alpha)$ has the continuation value if the agent, upon observing her wealth, decides an observation date $\tau$ periods from now,

\footnotetext{
${ }^{12}$ To be concrete, think about the way the transaction for the purchase of a house is typically done in the US. On the day of the closing the buyer typically uses a certified check -a liquid asset in our parlance. The funds of this liquid asset are typically transferred from a higher yield account one or two days before.
} 
leaving $a, d, \alpha$ unchanged:

$$
\begin{aligned}
\bar{V}(a, d, \alpha) & =\max _{\tau} \int_{0}^{\tau} e^{-\rho t} U\left(d e^{-t \delta}\right) d t \\
& +e^{-\rho \tau} \int_{-\infty}^{\infty} V\left(a\left(1-\phi_{o}\right) R(s, \tau, \alpha), d e^{-\delta \tau}, \alpha\right) d N(s) .
\end{aligned}
$$

The value $\hat{V}(a, d)$ has the continuation value for the policy where the agent, upon observing her wealth, decides to adjust her durable stock, so that by (5) the post-adjustment initial stock of durables is $d^{\prime}=a+d\left(1-\phi_{T}\right)-a^{\prime}$. She also decides a new observation date $\tau$ and the share of risky assets $\alpha^{\prime}$ :

$$
\begin{aligned}
\hat{V}(a, d) & =\max _{a^{\prime}, \tau, \alpha^{\prime}} \int_{0}^{\tau} e^{-\rho t} U\left(\left[a+d\left(1-\phi_{T}\right)-a^{\prime}\right] e^{-t \delta}\right) d t \\
& +e^{-\rho \tau} \int_{-\infty}^{\infty} V\left(a^{\prime}\left(1-\phi_{o}\right) R\left(s, \tau, \alpha^{\prime}\right),\left[a+d\left(1-\phi_{T}\right)-a^{\prime}\right] e^{-\delta \tau}, \alpha^{\prime}\right) d N(s) .
\end{aligned}
$$

Before studying the solution of the problem with information and trading cost we analyze three special cases. First, we discuss the frictionless problem: $\phi_{o}=\phi_{T}=0$. This case highlights what patterns of savings, consumption and risk exposure are preferred by the agent. Once we reintroduce the costs, the agent will trade-off paying these costs with achieving a profile of consumption and risk exposure as close as possible to the frictionless one. Second, we discuss the durable goods model in the presence of observation cost only (without trading cost). This model, which is novel in the literature, is useful to understand the degree of inaction that comes exclusively from the observation cost in the context of the durable good model. Third, we present the model with trading cost only. These analysis provide simple benchmarks for the more general model with both information and transactions cost.

\subsection{The frictionless problem $\left(\phi_{T}=\phi_{o}=0\right)$}

In the frictionless model we define total wealth as $w=a+d$ and consider the problem in continuous time (i.e. time between observations $\tau \downarrow 0$ ). The law of motion for wealth is

$$
\mathrm{d} w=[-\theta \delta+(1-\theta)(\alpha \mu+(1-\alpha) r)] w \mathrm{~d} t+(1-\theta) \alpha \sigma w \mathrm{~d} Z
$$

where $\theta$ denotes the fraction of wealth invested in durables, so that $d=\theta w$, and $(1-\theta) w$ is the amount invested in a portfolio with continuously compounded return $R$ given by (2). ${ }^{13}$ This portfolio is continuously rebalanced to have a fraction of risky assets $\alpha$, which is a choice

\footnotetext{
${ }^{13}$ This specification assumes that durable goods must be purchased (i.e. cannot be rented).
} 
variable for the agent. We use $Z$ for a standard Brownian motion. The Bellman equation is:

$$
\begin{aligned}
\rho v(w)=\max _{\theta, \alpha} & \left\{U(\theta w)+v^{\prime}(w)[-\theta \delta+(1-\theta)(\alpha \mu+(1-\alpha) r)] w\right. \\
& \left.+\frac{1}{2} v^{\prime \prime}(w) \sigma^{2}(1-\theta)^{2} \alpha^{2} w^{2}\right\}
\end{aligned}
$$

The optimal policy for this problem has:

$$
\begin{aligned}
\theta & =\frac{1}{\gamma} \frac{\rho}{(\delta+r)}-\frac{1-\gamma}{\gamma} \frac{\left[r+\frac{1}{2}(\mu-r)^{2} /\left(\gamma \sigma^{2}\right)\right]}{\delta+r} \\
\alpha(1-\theta) & =(\mu-r) /\left(\sigma^{2} \gamma\right) .
\end{aligned}
$$

Few comments are in order. This version of the durable consumption model with no transaction/observation cost maps directly into the standard Merton's portfolio choice and savings model with non-durable consumption. In Merton's model the optimal policy is to keep the ratio of consumption to wealth constant (say in the log case equal to $\rho$ ), and to rebalance the portfolio to keep a constant fraction of wealth, equal to $(\mu-r) /\left(\sigma^{2} \gamma\right)$, invested in the risky asset. In the problem with durable goods and no trading/observation costs the agent continuously observes her wealth, adjusts her stock of durable goods, and the size and composition of her financial assets. The mapping with Merton's model is straightforward: the per-period user cost of the durable good, $(r+\delta) d$, corresponds to the consumption flow per period in Merton's model. Equation (11) shows that in this case the agent keeps the ratio of durable to total wealth constant. For instance, in the 'log' case $(\gamma=1)$, the expression gives $\theta=\rho /(\delta+r)$, exactly as in Merton's model. Equation (12) shows that the fraction invested in the risky asset is the same as in Merton's model, once we take into account that the durable good behaves as a risk-less asset. Also, notice that as $\delta \rightarrow \infty$, then $\theta \rightarrow 0$. Hence the quantity of durables that is consumed at each point is increasing in the time discount and decreasing in the user cost of the durables that appears in the denominator.

\subsection{The problem with observation cost only $\left(\phi_{o}>0, \phi_{T}=0\right)$}

This section studies the problem assuming an observation cost $\phi_{o}>0$ but no cost of trading in durables $\phi_{T}=0$. In this case we have that $\hat{V}(a, d) \geq \bar{V}(a, d, \alpha)$ for all $(a, d, \alpha)$, because the option to set $a^{\prime}=a, \alpha^{\prime}=\alpha$ and $d^{\prime}=d$ in problem (9) gives $\bar{V}(a, d, \alpha)$. Hence the agent will trade and adjust her durables every time she chooses to observe her wealth, i.e. the agent will synchronize observing and trading. This result is the same as in the rational inattention model of non-durable goods by Abel, Eberly, and Panageas (2009), although for different reasons. The difference is that in the models with non-durable consumption the 
agent holds resources in a low yield transaction account, and as a consequence she chooses to optimally synchronize the time of observation and trade, even in the presence of strictly positive separate trade and observation costs. ${ }^{14}$

For $\phi_{T}=0$ the budget constraint after paying the observation cost $\left(\phi_{o}\right)$ is: $a^{\prime}+d^{\prime}=a+d$, and the Bellman equation can be written as a function of only one state, $w \equiv a+d$, and letting $v(a+d)=V(a, d)$ :

$$
\begin{aligned}
v(w) & =\max _{d^{\prime}, \tau, \alpha} \int_{0}^{\tau} e^{-\rho t} U\left(d^{\prime} e^{-t \delta}\right) d t \\
& +e^{-\rho \tau} \int_{-\infty}^{\infty} v\left(\left[\left(w-d^{\prime}\right)\left(1-\phi_{o}\right) R(s, \tau, \alpha)+d^{\prime} e^{-\delta \tau}\right]\right) d N(s)
\end{aligned}
$$

It is easy to see that if $U$ is homogeneous of degree $1-\gamma$, so is $v$, and hence the optimal choice of $d^{\prime}$ will be a fraction of $w$. We let $d^{\prime}=\theta w$ and use homogeneity to obtain:

$$
\begin{aligned}
v(1) & =\max _{\theta, \tau, \alpha} \int_{0}^{\tau} e^{-\rho t}\left(\theta e^{-t \delta}\right)^{1-\gamma} /(1-\gamma) d t \\
& +e^{-\rho \tau} v(1) \int_{-\infty}^{\infty}\left[(1-\theta)\left(1-\phi_{o}\right) R(s, \tau, \alpha)+\theta e^{-\delta \tau}\right]^{1-\gamma} d N(s)
\end{aligned}
$$

This equation shows that in this case $\alpha$ is not equal to the one in Merton's model. The reason is that total wealth at the end of the observation period of length $\tau$ is the sum of a constant (i.e. the deterministic value for the depreciated stock of durables) and a log normal random variable. Since this sum is not log-normal Merton's formula does not hold. Nevertheless, for the numerical examples considered below, the formula provides an accurate approximation.

Solving this problem reduces to solving 4 equations in 4 unknowns, namely $v(1), \alpha, \tau$, $\theta$. These equations, whose analytics appear in Online Appendix AA - 2.2, are the three first order conditions for $\alpha, \tau$ and $\theta$, and equation (13) evaluated at the optimal choices: $\alpha^{*}, \tau^{*}$ and $\theta^{*}$. Equation (13) shows that, as in Duffie and Sun (1990), optimal policy prescribes that the agent observes the value of the portfolio at equally spaced time intervals: $\tau^{*}$. Naturally, every observation generates an adjustment of the durable stock since $\phi_{T}=0$ in this setup. ${ }^{15}$ Equation (13) also shows that, as in Grossman and Laroque (1990), the policy dictates an optimal return point that is constant, i.e. after every adjustment the agent returns to the

\footnotetext{
${ }^{14}$ As shown in Table 1 and 2 this is inconsistent with the data for the Italian investors, who observe the value of their investment about three times more often than trade. Motivated by this, we will return to the general case with strictly positive cost of transferring-adjusting durable goods.

${ }^{15}$ Notice that our formulation of the agent problem subject to observation costs $\left(\phi_{o}>0\right)$ but without trading costs $\left(\phi_{T}=0\right)$ restricts the agent choices so that she takes no action in the interval of length $\tau$ between observation dates. But between observation dates the agent could have chosen to trade and adjust the durable goods. In Online Appendix AA - 3 we discuss the conditions under which eliminating this restriction does not change the optimal policy.
} 
Figure 3: Inaction spells $\tau$ as $\phi_{o}$ varies

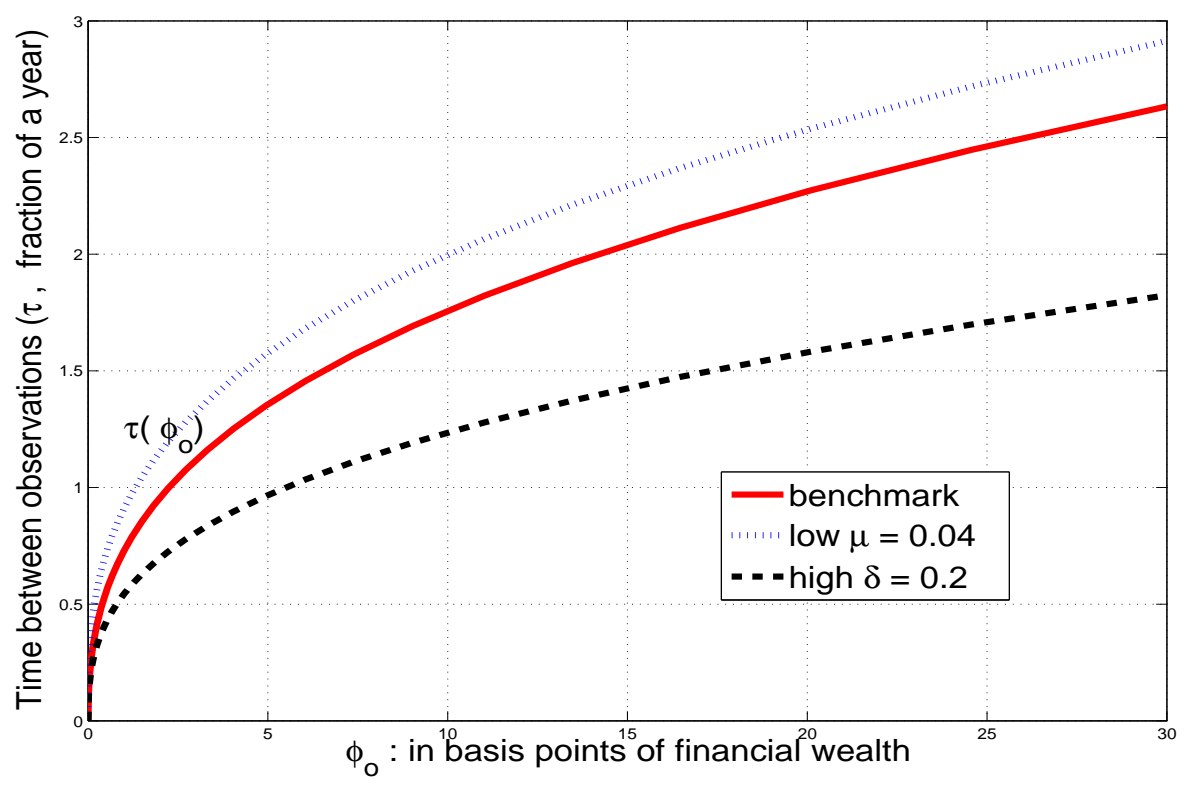

Note: The model parameters are (all annualized) $\gamma=4, \rho=0.02, \mu=0.06, \sigma=0.16, r=$ $0.03, \delta=0.10$ and $\phi_{T}=0.00$ basis points.

same value of $a / d=\left(1-\theta^{*}\right) / \theta^{*}$. Interestingly, the optimal return point for this model is quite similar to the one from the frictionless model for small values of the observation cost; for the parameter values in the ranges used in Figure 3 we have that $\theta=0.236$ and $\alpha=0.383$ in the frictionless benchmark, while $\theta=0.238$ and $\alpha=0.382$ in the model with costly observations. Overall, the frictionless model provides a good approximation to the optimal $\alpha$ and $\theta$ when the frictions are small, in the order of those considered in the calibrations of Section $5 .{ }^{16}$

The optimal choice of $\tau$ trades off costs and benefits: the cost is that a higher frequency of observation implies greater attention costs for the agent. The benefit is that by retrieving information more frequently (smaller $\tau$ ) the agent can do a better job at smoothing consumption across states (high and low asset returns) and across periods. Because of this, the optimal inaction interval $\tau^{*}$ depends on the benefit from investing in the risky assets (measured by $\mu, r$ and $\sigma$ ), on the depreciation rate of the durable good $(\delta)$, on the observation $\operatorname{cost} \phi_{o}$ and on the agent degree of risk aversion $(\gamma)$. Figure 3 plots the optimal value of $\tau$ as a function of the cost $\phi_{o}$ for three different sets of parameter values. As expected, $\tau^{*}$ is increasing in the cost $\phi_{o}$. When the observation cost is small the optimal inaction interval $\tau$ has an elasticity of about $1 / 2$ with respect to the observation cost. This elasticity reflects

\footnotetext{
${ }^{16}$ More evidence on the optimal values of $\theta$ in the different models appears in Table 6 below. The gap with the optimal return of the frictionless model increases if a large cost $\phi_{o}$ is used, or if the excess return of the risky asset and the depreciation rate of the durable are large.
} 
the fact that the first order condition of the value of the problem with respect to $\tau$ is flat around the optimum. In other words, the benefits of a better consumption smoothing are "second order". ${ }^{17}$ Note that for a given $\phi_{o}$, a reduction in the return of the risky asset from 6 to 4 percent reduces the expected change in wealth invested in the financial asset, hence the agent observes less often. Furthermore, if we increase the depreciation rate from 10 to 20 percent, the flow of durable consumption decreases faster, hence the agent observes and trades more often. To quantify the inertia implied by this model note that an observation cost in the order of 25 basis points of wealth produces one transaction (i.e. observation and trade) every 2.5 years, a magnitude that is comparable to what is seen in the data for the Italian investors from the SHIW sample (see Table 2). For a stock of assets of 50,000 euros, in the ballpark of the observations for the investors of the SHIW sample, our durable goods model implies that cost of one observation is about 125 euros. A more thorough comparison between the model predictions and the Italian data appears in Section 5.2, where we will show that when transactions costs are also present the observation costs that are needed to match the data become small.

\subsection{The problem with adjustment costs only $\left(\phi_{o}=0, \phi_{T}>0\right)$}

In order to compare the effects and magnitudes of trade cost with observation costs, in this section we consider the case where there are only transaction cost. The set up is closely related, but as discussed later not identical, to the one in Grossman and Laroque (1990). Since $\phi_{o}=0$ agents observe their wealth continuously, and trade only when the ratio of durables goods to financial wealth is either too high or too low, at which time they pay the fixed cost, rearrange the portfolio, trade and adjust their durable stock. In particular, we can describe the optimal decision rule by three numbers: $\underline{\mathbf{a}}$, $\hat{\mathbf{a}}$, and $\overline{\mathbf{a}}$. Denoting $\mathbf{a}(t)=a(t) / d(t)$, the agent remains inactive as long as $\mathbf{a}(t)$ is between $\underline{\mathbf{a}}$ and $\overline{\mathbf{a}}$, and as soon as it hits either barrier she pays the transaction cost, rearrange the portfolio weight $\alpha$ if appropriate, and adjust the durable stock so as to have a post-adjustment ratio of â. Denoting the value function of the agent by $V(a, d ; \alpha)$, we have that for $a / d \notin[\underline{\mathbf{a}}, \overline{\mathbf{a}}]$

$$
V(a, d, \alpha)=\max _{a^{\prime}, d^{\prime}, \alpha^{\prime}}\left\{V\left(a^{\prime}, d^{\prime}, \alpha^{\prime}\right): a^{\prime}+d^{\prime}=a+d\left(1-\phi_{T}\right)\right\}
$$

\footnotetext{
${ }^{17}$ See Alvarez, Lippi, and Paciello (2009) and Reis (2006b) for an analytical characterization of the $1 / 2$ elasticity with respect to the observation cost in a stylized version of a similar problem, and Reis (2006a) and Abel, Eberly, and Panageas (2007) for a similar result for two related models with non-durable goods.
} 
where we denote the value of the optimal weight as $\hat{\alpha}$. In the range of inaction $a / d \in[\underline{\mathbf{a}}, \overline{\mathbf{a}}]$ we have the familiar continuous time Hamilton-Jacobi-Bellman equation:

$$
\rho V(a, d, \hat{\alpha})=\frac{d^{1-\gamma}}{1-\gamma}+V_{a}(a, d, \hat{\alpha}) a[r+\hat{\alpha}(\mu-r)]-V_{d}(a, d, \hat{\alpha}) d \delta+\frac{1}{2} V_{a a}(a, d, \hat{\alpha}) a^{2} \hat{\alpha}^{2} \sigma^{2} .
$$

Figure 4: Expected time between adjustments w.r.t. $\phi_{T}$

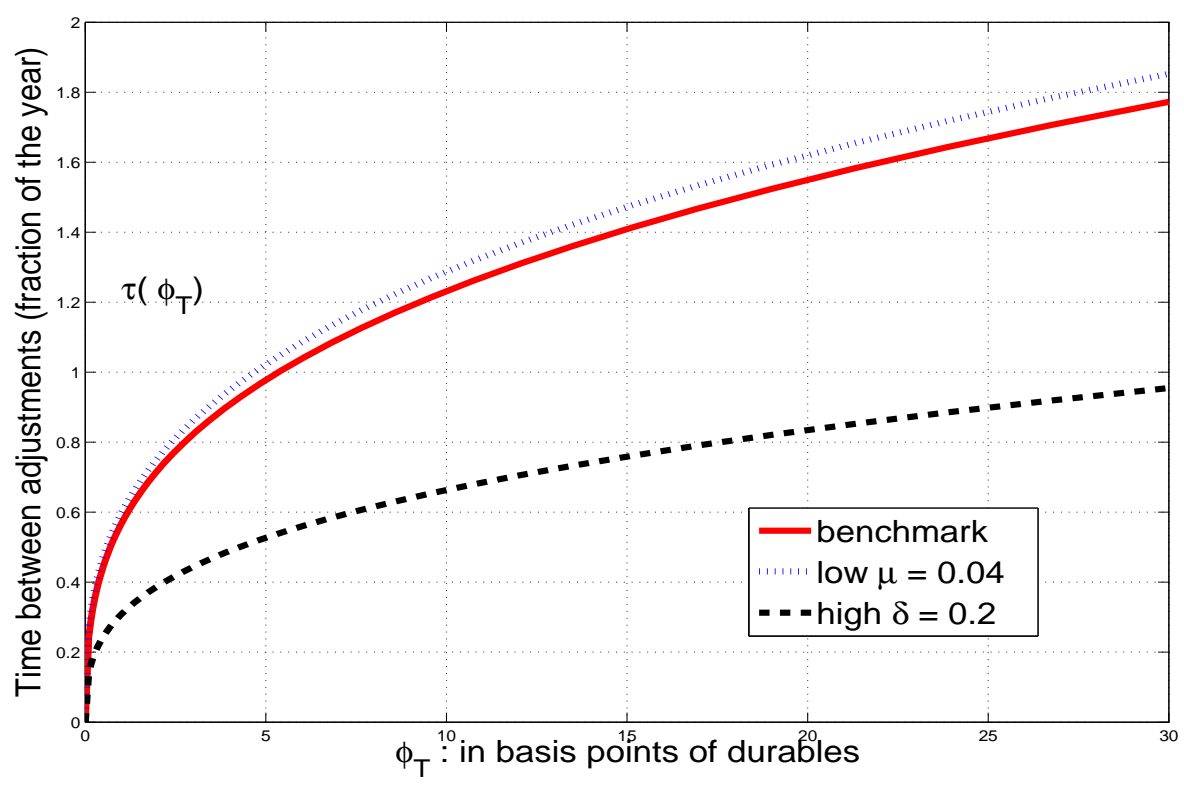

Note: The model parameters are (all annualized) $\gamma=4, \rho=0.02, \mu=0.06, \sigma=0.16, r=$ $0.03, \delta=0.10$ and $\phi_{o}=0.00$ basis points.

The main difference with the model in Grossman and Laroque (1990) is that we allow the agent to rearrange the portfolio weight $\alpha$ only at the time of a trade and adjustment of durables while they, as well as Stokey (2009), allow continuous adjustment on that margin. Our model can thus be interpreted as one where the adjustment cost applies to the management of assets. In the Online Appendix AA - 2.3 we fill in the details of the characterization of the optimal decision rule and describe the characterization of the expected time between successive adjustments. Figure 4 shows the behavior predicted by this model for a range of values of the transaction cost $\phi_{T}$. The expected time between adjustments is increasing in the level of the transaction cost. The figure also shows that the expected time between adjustment is decreasing in the depreciation rate $\delta$ and increasing in the expected return $\mu$. The logic behind these effects is analogous to the one discussed in Section 4.2 for the model with the observation cost. To compare the outcomes of the two models the value of one cost must be normalized, so that the dollar cost $\phi_{T} d$ equals the dollar cost $\phi_{o} a$ (this because the transaction and observation cost apply to different stocks). In the benchmark the value of 
$a / d \cong 3$, so that a given value of $\phi_{o}$ is comparable to a value of $\phi_{T}$ that is approximately three times smaller. Once this adjustment is done a comparison of the outcomes in Figure 3 and Figure 4 shows that observation and transaction cost give rise to similar levels of inaction in the different models. For example for $\phi_{T}=30$ the model predicts one trade every 1.8 years, the same number that is obtained in the model with observation costs when $\phi_{o}=10$.

Finally, the numerical solution of the model reveals that the expected time between adjustments has an elasticity with respect to the transaction cost $\phi_{T}$ close to $1 / 3$. This differs from the model with observation costs where the elasticity (w.r.t. $\phi_{o}$ ) is close to $1 / 2 .{ }^{18}$ We note that the workings of this model are quantitatively consistent with the findings of Stokey (2009). She builds a model with both durable and nondurable goods calibrated to interpret the durables as housing stock. She finds that with a transactions cost of about 10 percent agents adjust their durable goods every 24.7 years. Considering a transaction cost that is 1,000 times smaller (i.e. 10 basis points) our model predicts 0.8 adjustments per year, that is about 30 times smaller than the adjustment frequency in Stokey. These ratios are roughly in line with an elasticity of the frequency of adjustment with respect to the transaction cost close to $1 / 2$.

\subsection{The problem with observation and adjustment costs $\left(\phi_{o}>\right.$ $\left.0, \phi_{T}>0\right)$}

This section outlines the nature of the optimal policy for the problem in the presence of both transaction and observation costs. We show that in this case there is no perfect synchronization between portfolio observations and portfolio adjustments. A numerical illustration of the workings of the model is given in the next section.

The optimal decision rule for trading-transferring resources and adjusting the durable goods is of the $s S$ type. This is due to the homogeneity of the value function and to the fact that $\alpha$ is not a state in problem (9). Notice that for any fixed value of $\alpha$ the value function $V(a, d, \alpha)$ and the associated functions $\hat{V}(a, d)$ and $\bar{V}(a, d, \alpha)$ are all homogenous of degree $1-\gamma$ on $(a, d)$. The homogeneity follows from the assumptions of homogeneity of $U(\cdot)$, from the specification of the fixed cost of adjustment as proportional to the value of the current state $\left(\phi_{o} a\right.$ and $\left.\phi_{T} d\right)$, and from the linearity of the budget constraint.

Let $\hat{H}\left(a+d\left(1-\phi_{T}\right), a^{\prime}, \alpha, \tau\right)$ denote the objective function to be maximized on the right hand side of the Bellman equation for $\hat{V}$ in (9), given the wealth $a+d\left(1-\phi_{T}\right)$ after paying the trade cost. Notice that for fixed values of $\alpha$ and $\tau$ the function $\hat{H}(\cdot, \cdot, \alpha, \tau)$ is homogenous

\footnotetext{
${ }^{18}$ As the depreciation rate gets close to zero the elasticity converges to $1 / 2$ also in the transaction cost model. See Section 5.2 for more discussion of the effect of the drift/volatility of the state on these elasticities.
} 
of degree $1-\gamma$. Then we can consider the maximization:

$$
\{1-\hat{\theta}, \hat{\alpha}, \hat{\tau}\}=\arg \max _{\theta, \alpha, \tau} \hat{H}(1,1-\theta, \alpha, \tau) \quad \text { subject to } 0 \leq \theta \leq 1, \alpha, \tau \geq 0 .
$$

The homogeneity implies that the optimal decision rules for a generic state $(a, d)$ if the agent trades and adjusts the durable stock are given by:

$$
a^{\prime}=(1-\hat{\theta})\left(a+d\left(1-\phi_{T}\right)\right), \quad d^{\prime}=\hat{\theta}\left(a+d\left(1-\phi_{T}\right)\right),
$$

and that the optimal choices of $\tau$ and $\alpha$ are independent of $(a, d)$. For notation convenience we use $\mathbf{a} \equiv a / d=(1-\theta) / \theta$ to denote the normalized ratio of assets to durables. Let $\bar{H}(a, d, \alpha, \tau)$ be the objective function to be maximized on the right hand side of the Bellman equation for $\bar{V}$ in equation (8) given the state $(a, d, \alpha)$. Notice that for fixed $(\alpha, \tau)$ the function $\bar{H}(\cdot, \cdot, \alpha, \tau)$ is homogenous of degree $1-\gamma$. Consider the problem:

$$
\bar{\tau}(\mathbf{a}, \alpha)=\arg \max _{\tau \geq 0} \bar{H}(\mathbf{a}, 1, \alpha, \tau)
$$

where $\bar{\tau}$ is a function of $a / d$ because of the homogeneity of $\bar{H}$. Now consider an agent with $\alpha=\hat{\alpha}$ and durable stock $d$, who pays the observation cost and discovers her financial wealth (net of the observation cost) to be $a$. In this case, using $\mathbf{a} \equiv a / d$, the agent will trade and adjust if

$$
\bar{V}(\mathbf{a}, 1, \hat{\alpha})<\hat{V}(\mathbf{a}, 1)
$$

where we have used the homogeneity of $\hat{V}(\cdot)$ and $\bar{V}(\cdot, \hat{\alpha})$. Let

$$
\bar{I} \subset \mathbb{R}_{+} \equiv\{\mathbf{a}: \bar{V}(\mathbf{a}, 1, \hat{\alpha})>\hat{V}(\mathbf{a}, 1)\},
$$

then the optimal policy is of the form:

$$
\begin{aligned}
& \mathbf{a} \in \bar{I} \Longrightarrow \mathbf{a}^{\prime}=\mathbf{a}, \tau=\bar{\tau}(\mathbf{a}, \hat{\alpha}), \\
& \mathbf{a} \notin \bar{I} \Longrightarrow \mathbf{a}^{\prime}=\hat{\mathbf{a}}=\frac{1-\hat{\theta}}{\hat{\theta}}, \quad \tau=\hat{\tau} .
\end{aligned}
$$

The optimal policy is as follows. The set $\bar{I}$ defines an interval $[\underline{\mathbf{a}}, \overline{\mathbf{a}}]$ for values of the normalized state variable $\mathbf{a}$ where it is optimal for the agent not to trade and not to adjust the stock of durables. This happens because in the interior of the interval $\bar{V}(a, 1, \hat{\alpha})>\hat{V}(a, 1, \hat{\alpha})$, see Online Appendix AA - 2.4.

It is immediate that $\hat{\mathbf{a}} \in \bar{I}$, i.e. that the optimal return point $\hat{\mathbf{a}}$ is in the range of inaction. 
The size of the inaction interval depends on the fixed cost $\phi_{T}$, among other determinants. Thus if at the time of observing the state a falls in the interval $[\underline{\mathbf{a}}, \overline{\mathbf{a}}]$ the agent will find it optimal not to pay the fixed cost, to leave $d$ unaltered, and to set a new observation date $\tau(\mathbf{a})$ periods from now. Otherwise, if at the time of observing the state a falls outside the interval $[\underline{\mathbf{a}}, \overline{\mathbf{a}}]$, then the agent will pay the $\operatorname{cost} \phi_{T} d$, adjust the stock of durables, and set the new ratio of financial assets to durables to $\hat{\mathbf{a}}$. She will also set a new observation date $\hat{\tau}$ periods from now. The analysis shows that along an optimal path there will be instances where the agent will pay the observation cost but will not trade, as in the data for Italian investors displayed in Table 1 and Table 2.

\section{A Quantitative Exploration}

In this section we analyze some quantitative implications of the model by means of numerical solutions. First, we describe the decision rule, then we solve the model for different parameters values and develop some comparative statics to illustrate its workings. Finally, we use the numerical solution to relate the model to moments taken from the Italian investors' data.

\subsection{Decision rules}

The horizontal axis of Figure 5 displays the values of the ratio of the financial assets to durable goods $\mathbf{a} \equiv a / d$, right after the agent has observed the value of financial assets, and before deciding whether to trade and to adjust the durable stock. As discussed above, the optimal decision rule about adjusting the durables is of the $s S$ type. The two vertical bars at $\underline{\mathbf{a}}$ and $\overline{\mathbf{a}}$ denote the threshold values that delimit the inaction region. The vertical bar at $\hat{\mathbf{a}}$, inside the inaction region, denotes the optimal return point after an adjustment. As was the case in Section 4.2 for small frictions the value of the optimal return point is very close to the one from the frictionless model. ${ }^{19}$

The optimal decision after an observation is made of two rules: the first rule is whether (and by how much) to adjust the durable stock, the second rule gives a date for the next observation. The adjustment decision, after observing the value of the assets, depends on the location of the state $\mathbf{a}$. The middle panel contains the range of inaction, where the agent chooses not to adjust her financial asset and durable stock. Outside of this region, the agent will pay the adjustment cost $\phi_{T} d$, trade and adjust her financial asset and stock of durables to the values $\left(a^{\prime}, d^{\prime}\right)$ that satisfy $a^{\prime} / d^{\prime}=\hat{\mathbf{a}}$. The adjustments that occur to the left of $\underline{\mathbf{a}}$ involve

\footnotetext{
${ }^{19}$ For the values used in Figure 5, comparing the ratio of durables to total wealth $\hat{\theta} \equiv d^{\prime} /\left(a^{\prime}+d^{\prime}\right)$ defined in equation (16), with the corresponding ratio in the frictionless model where $\phi_{o}=\phi_{T}=0$, denoted by $\theta$, shows that $\hat{\theta}=0.238$, while $\theta=0.237$.
} 
Figure 5: Optimal Decision rule (normalizing $d=1$ )

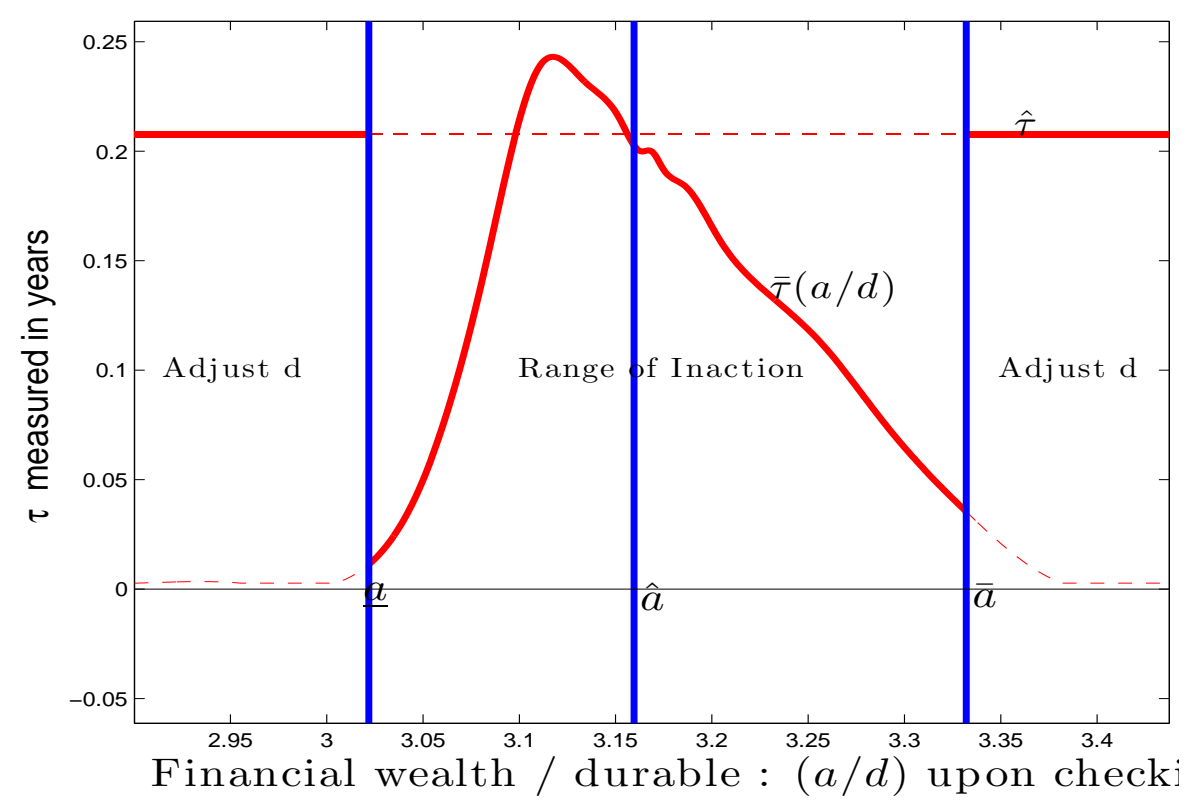

Note: Benchmark parameter values are $\gamma=4$, annualized: $\rho=0.02, \mu=0.06, \sigma=0.16, r=$ $0.03, \delta=0.10$, and $\phi_{o}=0.01$ basis points,$\phi_{T}=0.5$ basis points.

a sale of part of the durable stock $d$, while the ones to the right of $\overline{\mathbf{a}}$ involve purchases that add to the durable stock $d$. The discontinuous solid line in Figure 5 displays the optimal time until the next observation. This rule is made of two functions. One is the optimal time until the next observation contingent on trading, which is given by the constant value $\hat{\tau}$. This is analogous to the optimal rule in Duffie and Sun (1990) and in Section 4.2, where each observation is also a trade. The other function gives the optimal time until the next observation contingent on not trading. This function depends on the state $\mathbf{a}$, and is denoted by $\bar{\tau}(a / d)$ in the figure. Thus, the optimal decision rule (solid line) is given by $\bar{\tau}(\cdot)$ in the inaction region, and by $\hat{\tau}$ in the adjustment regions.

We notice several properties of the optimal time until the next observation:

1. the function $\bar{\tau}(\cdot)$ is hump shaped,

2. the value of $\bar{\tau}(\hat{a})=\hat{\tau}$,

3. the values of $\bar{\tau}(\underline{a})$ and $\bar{\tau}(\bar{a})$ are strictly positive

4. the function $\bar{\tau}(\cdot)$ reaches zero for values of $a / d$ strictly inside the adjustment regions.

5. the maximum of $\bar{\tau}(\cdot)$ lies to the left of $\hat{a}$, 
The reason why point 1 holds, is that when the agent is inside the inaction region but close to the borders, she realizes that the state $(\mathbf{a})$ is likely to reach the adjustment region shortly, and hence it is optimal to revise the information soon. In the middle of the inaction region, instead, the expected time before reaching the adjustment region is greater, and thus the optimal time to the next revision is longer. The reason why point 2 holds is that if, upon observing, the value of $a / d$ happens to coincide with the optimal return point $\hat{\mathbf{a}}$, then the objective function w.r.t. $\tau$ is the same as the one when adjustment is considered (i.e. $\hat{V}$ ), and thus so is the value for the optimal inaction interval. Point 3 holds because if $\tau$ was zero on the boundary, the agent would be paying the observation cost an arbitrarily large number of times in a short period of time. Point 4 holds because if $a / d$ is large, and the agent is forced not to trade (that is the assumption underlying the definition of the function $\bar{\tau}$ ), she will choose to review immediately and trade. Finally, the reason why point 5 holds is that in our parametrization the ratio $a(t) / d(t)$ has a drift to the right (when it is not controlled by adjustments), approximately equal to the sum of the expected return on the financial asset plus the depreciation rate. Thus when $a / d$ is close to $\hat{\mathbf{a}}$, but to its left, the agent forecasts to be in the inaction for a time longer than $\hat{\tau}{ }^{20}$

Table 5: Observation and trade frequency (per year) as $\frac{\phi_{T}}{\phi_{o}}$ varies

\begin{tabular}{lrcccrcr}
\hline \hline$\phi_{o}(\mathrm{bp})$ & $\phi_{T}(\mathrm{bp})$ & \# observ. & \# trades & $\frac{\text { \#trades }}{\text { \#observ. }}$ & $\frac{\phi_{T}}{\phi_{o}}$ & $\hat{\mathbf{a}}$ & $\frac{\phi_{T}}{\phi_{o}} \frac{d}{a}$ \\
\hline \hline 0.01 & 0.1 & 7.7 & 3.6 & 0.47 & 10 & 3.18 & 3 \\
0.01 & 0.5 & 7.1 & 2.1 & 0.29 & 50 & 3.16 & 16 \\
0.01 & 2.5 & 5.2 & 1.3 & 0.25 & 250 & 3.10 & 81 \\
0.01 & 10.0 & 4.9 & 0.8 & 0.16 & 1,000 & 3.02 & 331 \\
\hline 0.05 & 0.5 & 4.0 & 2.0 & 0.50 & 10 & 3.15 & 3 \\
0.05 & 2.5 & 3.3 & 1.2 & 0.37 & 50 & 3.10 & 16 \\
0.05 & 12.5 & 3.0 & 0.7 & 0.24 & 250 & 3.00 & 83 \\
0.05 & 50.0 & 2.6 & 0.5 & 0.18 & 1,000 & 2.88 & 347 \\
\hline $0.01 / 3$ & 0.1 & 12.8 & 3.8 & 0.29 & 30 & 3.19 & 9 \\
0.02 & 100.0 & 3.3 & 0.4 & 0.11 & 5,000 & 2.81 & 1,779 \\
\hline \hline
\end{tabular}

Notes: The variables $\phi_{o}$ and $\phi_{T}$ are measured in basis points (bp). The other parameters are $\gamma=4, \delta=0.10, \rho=0.02, r=0.03, \mu=0.06, \sigma=0.16$ per year. The variable $\hat{\mathbf{a}} \equiv \frac{1-\theta}{\theta}$ is the optimal return point, given by the ratio of the value of assets (net of observation cost) and that of durables (net of transaction cost).

\footnotetext{
${ }^{20}$ In Alvarez, Lippi, and Paciello (2009) we study a stylized version of this problem, for which we derive analytically the properties of the decision rules discussed here. In particular, the shape displayed in Figure 5 follows from the combination of two limit cases studied in that paper: the case with uncertainty and no-drift on the state, and the case of no-uncertainty and drift on the state.
} 


\subsection{Some calibration exercises}

Given the nature of the decision rule it is immediate to see that $a(t) / d(t)$ follows a stationary Markov process with a unique invariant measure. Table 5 shows how the number of observations and trades varies for different combination of the observation and transaction costs $\phi_{o}$ and $\phi_{T}$. In this exercise the parameters $\gamma, r, \mu, \sigma, \rho$ are set to values that are common in the literature, see e.g. Abel, Eberly, and Panageas (2009), to facilitate comparison of results. The depreciation parameter is set to ten percent annual $(\delta=0.10)$, so that the half life of the durable good is between 6 and 7 years, which seems a reasonable value for the kind of durable goods that we observe (see Table 10). The comparative statics for some of these parameters is discussed below. The first two columns in the table report the values of $\phi_{o}$ and $\phi_{T}$ used in the computation of each row. The columns \# observ. and \# trades report, respectively, the expected number of observations and the expected number of trades per year, under the invariant measure. The fifth column reports the ratio between these frequencies and the sixth column gives the ratio between the transaction over the observation cost. Since these costs apply to different aggregates ( $a$ and $d$, respectively), the next to column reports the optimal return point $\mathbf{a}=a / d$ which is used, in the last column, to compute the ratio between the transaction and observation costs properly scaled.

We use the numerical results of Table 5 to illustrate three main quantitative properties of the model with respect to the costs $\phi_{o}$ and $\phi_{T}$. First, the model generates substantial inaction with relatively small observation and transactions cost. For instance in the parameterization used in the second row of Table 5 (also used in Figure 5 ) the observation cost is $\phi_{o}=$ $0.01 / 10,000$ of the post-observation financial wealth (i.e. 1/100 of one basis point), and the trade cost is $\phi_{T}=0.5 / 10,000$ of the pre-adjustment stock of durable. Yet, in spite of these small costs, the expected number of observations per year is 7.1 and the average number of trades is 2.1 .

Second, we notice that keeping all the other parameters fixed the ratio between the frequency of trades and the frequency of observations is a monotone decreasing function of the ratio of the two costs: $\phi_{T} / \phi_{o}$. This can be seen by comparing the four rows in the upper part of the table, where $\phi_{o}=0.01$, with the four rows in the next panel, where $\phi_{o}=0.05$. The ratio $\phi_{T} / \phi_{o}$ is $10,50,250$, and 1,000 across the lines of each panel. Notice that as this ratio increases the ratio between the frequency of trades to the frequency of observations decreases. Moreover, notice that despite a 5 -fold increase in the level of both costs $\left(\phi_{T}, \phi_{o}\right)$ between the upper and the middle panel, a comparison across these panels shows that in the lines that share a common value of $\phi_{T} / \phi_{o}$ the ratio of trades to observation is essentially constant. For instance for $\phi_{T} / \phi_{o}=10$ the ratio between trades and observation is around 0.5 , irrespective of the level of the cost. This shows that the ratio between the frequency of 
observation and trade depends, approximately, on the ratio of the two costs. ${ }^{21}$

Third, the elasticity of the average number of observations per year with respect to the cost $\phi_{o}$ is a bit smaller than 0.4 . Theoretically we expect the elasticity to be between $1 / 3$ and $1 / 2$, based on the results in Alvarez, Lippi, and Paciello (2009). In that paper we show that the number of adjustments per unit of time has an elasticity of $1 / 2$ for three stylized versions of the model: the one with observation cost only, the one with adjustment cost only, and the one with both costs provided that the costs are small and that the drift of the state is small relative to its volatility. If, instead, the drift/volatility of the state is large, the elasticity is $1 / 3$ for small cost. In the model of this paper the relevant state is the $(\log )$ of $a(t) / d(t)$, which has a non negligible drift due mostly to the depreciation rate of durables, so the elasticity is between $1 / 3$ and $1 / 2$.

Table 6: Observations, trades and welfare loss in different models (per year)

\begin{tabular}{|c|c|c|c|c|c|}
\hline$\overline{\phi_{o}(\mathrm{bp})}$ & $\overline{\phi_{T}(\mathrm{bp})}$ & \# observ. & \# trades & $\overline{\mathbf{a}}$ & $\begin{array}{l}\text { Consumption loss } \\
\text { w.r.t. frictionless }\end{array}$ \\
\hline \multicolumn{6}{|c|}{ Model: No frictions } \\
\hline 0.00 & 0.00 & $\infty$ & $\infty$ & 3.22 & 0 \\
\hline \multicolumn{6}{|c|}{ Model: Observation cost only } \\
\hline $0.01 / 3$ & 0.00 & 17.1 & 17.1 & 3.20 & $0.03(\%)$ \\
\hline 0.02 & 0.00 & 7.3 & 7.3 & 3.19 & $0.07(\%)$ \\
\hline \multicolumn{6}{|c|}{ Model: Transaction cost only } \\
\hline 0.00 & 0.10 & $\infty$ & 4.1 & 3.19 & $0.05(\%)$ \\
\hline 0.00 & 100.00 & $\infty$ & 0.4 & 2.81 & $3.50(\%)$ \\
\hline \multicolumn{6}{|c|}{ Model: Observation \& transaction cost } \\
\hline $0.01 / 3$ & 0.10 & 12.8 & 3.8 & 3.19 & $0.07(\%)$ \\
\hline 0.02 & 100.00 & 3.3 & 0.4 & 2.81 & $3.52(\%)$ \\
\hline
\end{tabular}

Notes: The variables $\phi_{o}$ and $\phi_{T}$ are measured in basis points (bp). The other parameters are $\gamma=4, \delta=0.10, \rho=0.02, r=0.03, \mu=0.06, \sigma=0.16$ per year. The variable $\hat{\mathbf{a}} \equiv \frac{1-\theta}{\theta}$ is the optimal return point, given by the ratio of the value of assets (net of observation cost) and that of durables (net of transaction cost). $-{ }^{a}$ This loss gives the compensating variation in the annual flow of durable consumption (in \%) that is needed to equate the welfare level to the one obtained in the frictionless model (both value functions are evaluated at the â of the model with frictions).

Next, we calibrate the model to assess the importance of observation and transaction costs using the data for the Italian investors. As a reference we take two set of numbers from Table 2 corresponding to direct stock-holders from the UCS and another from all investors

\footnotetext{
${ }^{21}$ See Alvarez, Lippi, and Paciello (2009) for an analytical derivation of the conditions under which the ratio of the observation and trade frequency depends only on the ratio of the observation and trading costs, in a simpler model with a quadratic return function.
} 
for SHIW. We think of the UCS stock holder as representative of a pool of more sophisticated investors, while the data in SHIW are representative of the typical Italian investors. The sophisticated investor trades about 4 times a year, and observes about 12 times a year, so the ratio of trades per observation is 0.3 . Instead the typical investor trades about 0.4 times a year and observes about 3.6 times a year, so that the ratio of trades per observation is about 0.1. ${ }^{22}$ The third panel of Table 5 presents two calibrations chosen to match the behavior of these two investors. For an observation cost of $\phi_{o}=0.01 / 3$ basis point and a transaction cost of $\phi_{T}=0.1$ basis point the model predicts 12.8 observations and 3.8 trades per year, i.e. a ratio of 0.29 trades per observation. This parametrization gets close to the behavior of the sophisticated investor, matching the levels and the ratio of the observation and trade frequency. This suggests that the ratio between transaction and observation costs, measured in euros using the values of the stocks at the time of adjustment, is $\left(\phi_{T} / \phi_{o}\right) \times(d / a) \approx 10$ i.e. one order of magnitude. The simulation in the last line of the table uses an observation cost of $\phi_{o}=0.02$ basis point and a transaction cost of $\phi_{T}=100$ basis points. This produces 3.3 observations and 0.4 trades a year, with roughly 0.1 trades per observation. These figures are close to those of the typical Italian investor. In this case the ratio of the trade to the observation cost, measured in euros at the time of adjustment is $\left(\phi_{T} / \phi_{o}\right) \times(d / a) \approx 1,780$ or three orders of magnitude. Thus, to approximately match the behavior of the typical Italian investor, a very large ratio of the transaction to the observation cost is required, approximately 180 times larger than the one for the sophisticated investor.

Altogether, the calibration shows that the magnitude of the observation cost $\phi_{o}$ that is necessary to match observed patterns of behavior is small. For instance, if we use one percent of one basis point for a financial wealth of a 130,000 euros (which is about the median for the UCS sample of direct equity holder), the observation cost is about 13 euro cents. The adjustment cost for trading durables are also small in the simulation that we associate with the sophisticated investors, and larger (up to one percent) for the simulation that we associate with the typical Italian investor. These transaction costs may look small if they are interpreted as costs of trading durables, as they literally are in the model. But if the transaction cost is interpreted as a fixed costs in asset trading then these values, from a few up to 100 basis points, are consistent with recent asset-transaction cost estimates for the US in Bonaparte and Cooper (2009). This reinterpretation is fully consistent with our model since the costs are fixed (it is only for notation convenience that we model the two costs as applying to different stocks).

To quantify the relevance of these costs Table 6 compares the outcomes of this model

\footnotetext{
${ }^{22}$ Recall that the observation data for the SHIW investors are noisy as they are imputed from a regression on UCS data, see the note to Table 2.
} 
with the ones produced by the three special cases discussed in the previous section: the frictionless benchmark, the observation-cost only and the transaction-cost only. The analysis shows that transaction costs in the order of one percent of the durable stock are not negligible for the investor. Notice that even though the cost is paid on average once every 2.5 years its impact on welfare, measured by the compensating variation in the annual consumption flow, is about 3.5 percent. This is due to the fact that the good is durable, so that the flow value is approximately given by $c=(r+\delta) d$, so that a unit change in $d$ affects the period utility flow approximately by a factor $1 /(r+\delta)$. For the median investors, to which the model was calibrated, the welfare effect of the observation cost are much smaller, as a consequence of their smaller size. From Table 6 we conclude that, at the values of the transaction and observation cost that we focus on, the behavior of the model with both costs is very similar to one with the transaction cost only. We arrive to this conclusion by comparing the number of trades per year, as well as the post-trade ratio of financial assets to durables, for the two benchmark cases displayed in the two panels in the bottom of Table 6. In particular, a comparison of the "Transaction cost only" panel with the "Observation \& transaction cost" panel shows that the number of trades per year is essentially unaltered by the presence of the small observation costs. Moreover the consumption loss w.r.t. the frictionless benchmark is very small, in the order of 2 basis points of the annual consumption flow (say $0.05 \%$ vs $0.07 \%$ or $3.50 \%$ vs $3.52 \%$ ). Alternatively, these figures suggest that for the parametrizations considered in these panels observing between 3.3 to 12.8 times per year provides almost the same information as observing continuously.

We conclude the section with a remark on the asymmetry of the $\bar{\tau}(a / d)$ function discussed in point 5. Notice that if the process for $a(t) / d(t)$ has a strong drift, i.e. if the return on financial assets plus depreciation is large, then most adjustments will happen in the right adjustment region, and hence they will involve a liquidation of assets and a purchase of durables. The frequency with which $a(t) / d(t)$ hits the "sale" region relative to the "buy" region depends on the strength of the drift, which is approximately equal to $\alpha \mu+(1-\alpha) r+$ $\delta$, relative to the variability of this ratio, which is about $(1-\theta) \alpha \sigma \approx(\mu-r) /(\gamma \sigma)$ (see equation (12)). In Table 7 we show how this frequency varies with $\delta$ and $\sigma$. As expected from the direct effect on the drift, larger values of $\delta$ lead to a larger fraction of adjustments being purchases. For larger value of $\sigma$, the net effect is to decrease the exposure to risk (through equation (12)), so that the variability of $a(t) / d(t)$ actually decreases. Thus, for low $\sigma$, the variability of $a(t) / d(t)$ is high, and hence the process reach both thresholds more often, which explains why the fraction of sales is smaller for $\sigma=0.06$ than for $\sigma=0.16$. In our benchmark numerical example $98 \%$ of adjustments are purchases of durables (see Table 7 ). This comes close to the comparable figure for Italian investors that is $95 \%$ (see Table 10). 
Table 7: Durable trades in the model: Fraction of Purchases

\begin{tabular}{ccccccc}
\hline \hline & \multicolumn{4}{c}{ Depreciation Rate $(\delta)$} & \multicolumn{4}{c}{ Volatility $(\sigma)$} \\
& 0.05 & 0.10 & 0.15 & 0.06 & 0.16 & 0.26 \\
\cline { 2 - 7 } Benchmark parameters: $\gamma=4, \mu=0.06, \rho=0.02, r=0.03, \phi_{o}=0.01(\mathrm{bp}), \phi_{T}=0.5$ \\
\cline { 2 - 6 }
\end{tabular}

\section{Some evidence on the durable goods model}

This section contrasts two predictions of the durable goods model with data from the UCS 2003 and the SHIW 2004 survey. The first prediction pertains to the relation between the investor risk aversion and the frequency of observations. The second relates to the frequency of durable purchases and that of assets transactions.

\subsection{Observations and portfolio riskiness vs. risk aversion}

An increase in the degree of relative risk aversion has two effects in the model: first, it induces the investor to hold a safer portfolio; second, it increases the value of consumption smoothing. The first effect, whose strength depends on the attractiveness of the risky asset, as measured by its Sharpe ratio $(\mu-r) / \sigma$, lowers the value of information and implies that a more riskaverse investor chooses to observe her investments less frequently. This effect is akin to the one first studied by Verrecchia (1982) (see Corollary 1) and Peress (2004) (Theorem 2) who show that agents with a higher risk aversion have weaker incentives to obtain precise signals (i.e. information) about the return of the risky asset. ${ }^{23}$ In our context this channel relates to the frequency one gathers information about the value of the investments rather than to the quality of the signal received. The second effect, raises the value of information and thus, through this channel, more risk averse investors should observe more frequently.

Which of the two effects prevails in our model depends on parameters values. For large enough, yet realistic values of the Sharpe ratio $(\mu-r) / \sigma$, and small values of the cost $\phi_{T}, \phi_{o}$, the portfolio effect dominates the consumption-smoothing effect over a reasonable range of values of the degree of risk aversion. Hence, the frequency of observing ones' investments is lower for more risk averse investors. Table 8 shows that the share invested in the risky asset and the frequency of portfolio observations both decrease as the degree of relative risk aversion increases, for a parametrization of the costs that was shown to produce a reasonable

\footnotetext{
${ }^{23}$ Verrecchia assumes the utility function displays constant absolute risk aversion in wealth. Peress shows that the same result obtains if absolute risk aversion is decreasing in wealth, so that wealthier individuals invest more into risky assets and hence have greater incentive to acquire information.
} 
match of the behavior of the investor from the UCS survey (see Section 5.2).

Table 8: Effect of risk aversion $(\gamma)$ on trade and observation frequency

\begin{tabular}{|c|c|c|c|c|c|}
\hline$\gamma$ & Risky asset share & $\hat{\mathbf{a}}$ & \# observ. & \# trades & $\begin{array}{l}\text { \# trades } \\
\text { \# observ. }\end{array}$ \\
\hline 8 & 0.146 & 3.20 & 6.3 & 4.1 & 0.65 \\
\hline 7 & 0.167 & 3.20 & 6.4 & 3.9 & 0.62 \\
\hline 6 & 0.194 & 3.18 & 6.8 & 3.8 & 0.56 \\
\hline 5 & 0.234 & 3.18 & 6.8 & 3.6 & 0.52 \\
\hline 4 & 0.292 & 3.18 & 7.7 & 3.6 & 0.46 \\
\hline 3 & 0.389 & 3.22 & 8.4 & 3.6 & 0.43 \\
\hline 2 & 0.584 & 3.39 & 10.3 & 4.1 & 0.43 \\
\hline
\end{tabular}

Notes: $\overline{\overline{\text { The share in risky asset is computed by Merton's formula, i.e. } \alpha(1-\theta)}}=(r-$ $\mu) /\left(\gamma \sigma^{2}\right)$. The other model parameters $\rho=0.02, r=0.03, \mu=0.06, \sigma=0.16, \delta=0.10$ (all per year), $\phi_{o}=1 / 100(b p), \phi_{T}=1 / 10(b p)$.

We can test this prediction of the model because the UCS survey has an indicator of risk aversion patterned after the Survey of Consumer Finance. Investors are asked: "Which of the following statements comes closest to the amount of financial risk that you are willing to take when you make your financial investment: (1) a very high return, with a very high risk of loosing the money; (2) high return and high risk; (3) moderate return and moderate risk; (4) low return and no risk". ${ }^{24}$ Only $19 \%$ choose "low return and no risk", so most are willing to accept some risk if compensated by a higher return. A recent literature on eliciting preferences from survey data shows that direct questions on risk aversion are informative and have predictive power. ${ }^{25}$ Consistent with this literature, Figure 6 shows that the portfolio share invested in risky assets (direct and indirect stocks) is monotonically decreasing with our index of risk aversion; the correlation and its significance are confirmed in (unreported) regressions that control also for measures of investors assets, income and demographic characteristics, reassuring us about the reliability of our risk aversion indicator.

To analyze the model implications Table 9 shows regressions for different groups of the (log) number of times an investor observes his investments and the risk aversion indicator while controlling for endowment (log consumption) and demographic characteristics. We use three dummies for risk aversion, excluding the group with the highest risk aversion. Irrespective of which sample we use (the whole sample or that of the stockholders, total or direct) we find that more risk tolerant individuals observe their investments more frequently

\footnotetext{
${ }^{24}$ The question does not distinguish between relative and absolute risk aversion. But since we can control for wealth, we can allow the risk aversion indicator to reflect differences in risk preferences that do not arise from differences in endowments.

${ }^{25}$ See, among others, Barsky et al. (1997) and Guiso and Paiella (2008).
} 
than less risk tolerant ones, consistent with the prediction of the model. ${ }^{26}$

Figure 6: Share of risky assets vs. self-reported risk aversion

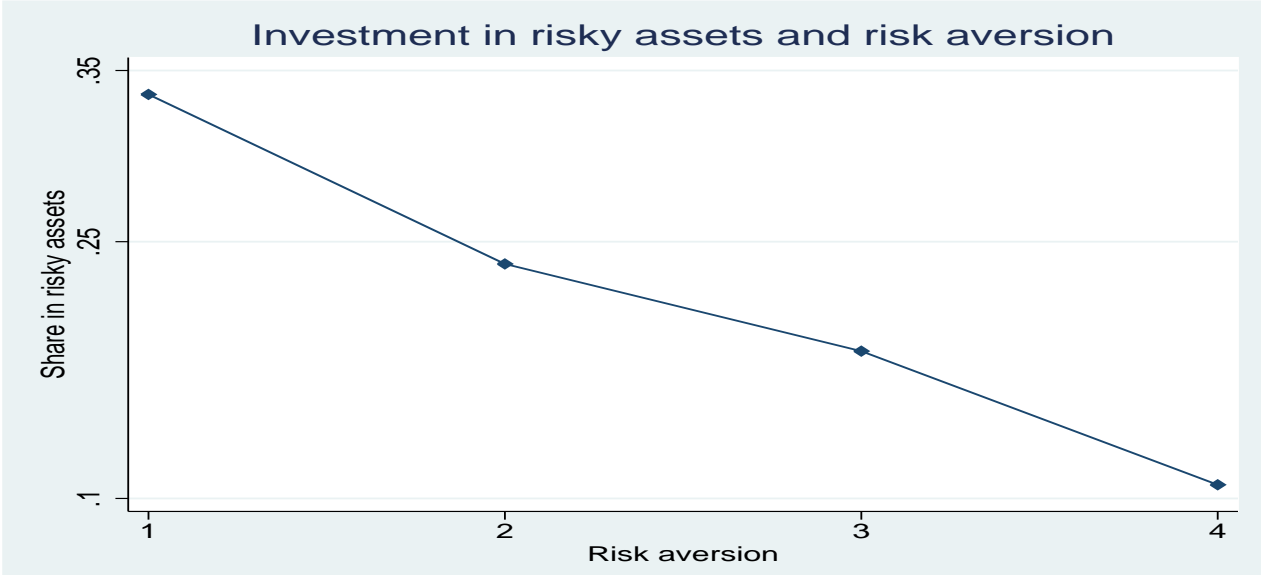

Note: The figure is based on the sample of investors (direct and in direct stockholders and holders of other risky assets) in the UCS sample. The share in risky assets is the value of risky financial assets in total financial assets. Risk aversion takes 4 values from very low (indicator equal to 1) to very high (indicator equal to 4), see Appendix A.

We notice that the predicted negative relation between risk aversion and the frequency of observations is a property of the model of assets trades and durable goods with attention costs but it is not specific to it. In fact the same prediction obtains in models with nondurable goods, assets trades and attention costs and can thus be viewed as a general test of models of assets trades with attention costs.

\subsection{The correlation between trades in assets and in durables}

The second test we consider in this section is specific to our durable goods model. By abstracting from the non-durable purchases, agents in our model trade only to adjust their purchase of durables, hence we expect that agents who are more active in purchasing durables are also more active in assets transactions.

We test this prediction using information in the SHIW 2004 survey on the frequency of durable purchases and the frequency of asset transactions of Italian households. In particular, the survey registers whether the household bought or sold durable goods in each of three categories: housing, vehicles and jewelry in the year prior to the interview. It also records

\footnotetext{
${ }^{26}$ Guiso and Jappelli (2007) using the 2003 UCS data find that the amount of time investors spend collecting financial information is negatively correlated with the risk aversion indicator which is also consistent with the model idea that risk aversion weakens investors incentives to obtain information about their investments, either by checking frequently their value (as in our model) or by obtaining costly signals.
} 
Table 9: Risk aversion and portfolio observations in the data

\begin{tabular}{|c|c|c|c|c|}
\hline \multicolumn{5}{|c|}{ Dependent Variable : log of Number of Observations per year } \\
\hline \multirow{2}{*}{$\begin{array}{l}\text { Risk Aversion Dummies: } \\
\text { Very Low } \gamma\end{array}$} & \multicolumn{2}{|c|}{$\begin{array}{c}\text { All Investors } \\
\text { (1456 obs.) }\end{array}$} & \multicolumn{2}{|c|}{$\begin{array}{c}\text { Direct }+ \text { Indirect } \\
\text { Stockholders (944 obs.) }\end{array}$} \\
\hline & & & $114^{* * *}$ & \\
\hline Low $\gamma$ & $0.66^{* * *}$ & - & $0.51^{* * *}$ & _ \\
\hline Medium $\gamma$ & $0.50^{* * *}$ & - & $0.35^{*}$ & - \\
\hline
\end{tabular}

Share Risky assets $\alpha \quad 1.67^{* * *} \quad 0.58^{* *}$

Three $\overline{\overline{\text { (one) asterisks denote that the null hypothesis of a zero coefficient is rejected by a }}}$ t-test with a 1 (10) per cent confidence level. Source: UCS 2003 survey. All regressions with controls (demographics, consumption, etc). Risk aversion is measured as answer to a question on risk and expected returns sought. High risk aversion is the excluded category.

Table 10: Fraction of Investors who adjusted the durables stock in 2004

\begin{tabular}{|c|c|c|c|c|c|}
\hline & $\begin{array}{c}\text { Jewelry } \\
\text { \& Antiques }\end{array}$ & $\begin{array}{c}\text { Cars } \\
\text { \& other }\end{array}$ & $\begin{array}{c}\text { Furniture } \\
\& \text { appliances }\end{array}$ & All & Housing $^{a}$ \\
\hline \multicolumn{6}{|l|}{ All investors (2,808 obs.) } \\
\hline & 0.09 & 0.15 & 0.37 & 0.47 & - \\
\hline$\%$ purchases $^{b}$ & 97 & 83 & $100^{c}$ & 95 & \\
\hline \multicolumn{6}{|l|}{ By Investor type } \\
\hline$<1$ per year (824 obs.) & 0.07 & 0.13 & 0.34 & 0.42 & 0.04 \\
\hline$\geq 1$ per year (1,984 obs.) & 0.12 & 0.20 & 0.45 & 0.57 & 0.06 \\
\hline
\end{tabular}

Source: SHIW - Bank of Italy. Notes: Statistics computed for 2,808 households with financial assets other than bank or postal account. For each category of durables, an adjustment means that the household records at least one purchase or one sale in 2004. $-{ }^{a}$ Measures the proportion of household who bought or sold a house over a 5-year window.

whether it has bought house appliances (furniture, electrical apparel, etc). Thus, even though we do not have the total number of purchases or sales, we have information on whether the household engaged in trading durables in any of these categories. The upper panel of Table 10 reports the fraction of investor/households who were active in each of these 4 categories. For instance, the fraction of investors who bought a durable in the car \& other transportation category in 2004 is $15 \%$. As a first check of the plausibility of the model prediction that asset trades and durable trades are correlated, the lower panel of the table shows that the fraction of investors who purchased durable goods in 2004 is higher among those who traded financial 
assets more often. ${ }^{27}$ Notice that if we condition on the sample of investors who traded more often (i.e. at least once in a year) the proportion of those who bought a car rises from 15 to $20 \%$. Notice that this same pattern is found in each of the various categories for which we have information on the durable purchases. This pattern is consistent with the model outlined in Section 4.4 if investors differ in the costs $\phi_{T}$ and $\phi_{o}$.

Figure 7: Durable vs. Portfolio trades in SHIW 2004

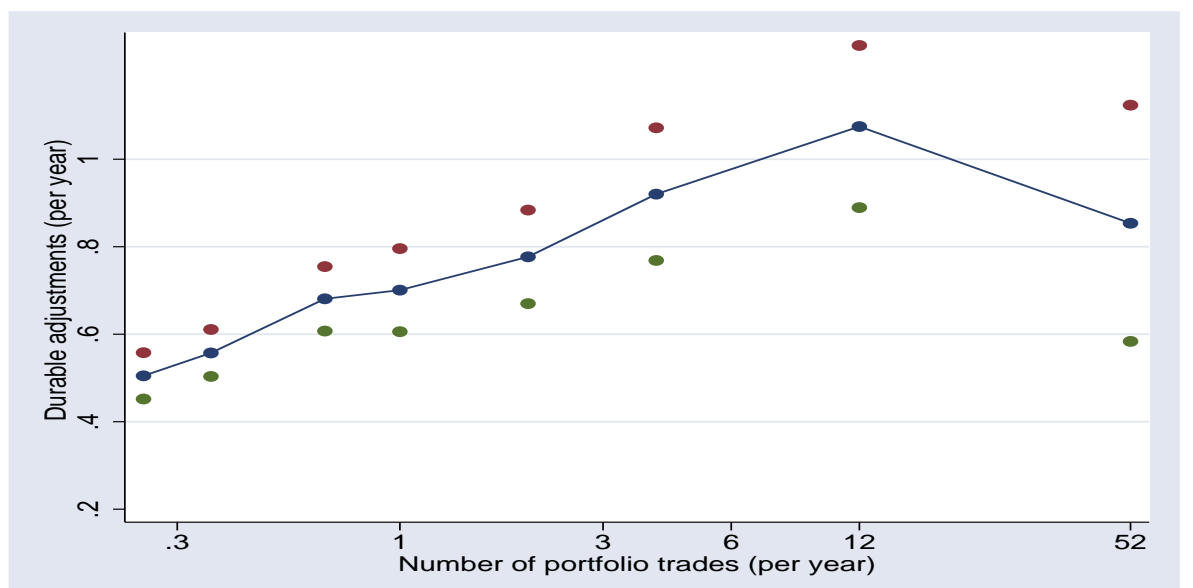

Note: Portfolio trades is the number of asset transactions in 2004 (categorical); Durable trades is a proxy for the number of durable transactions in 2004 (see the text). The line plots the mean of the durable trades indicator corresponding to each portfolio-trade-frequency bin. The dots denote 2 standard error bands around the mean.

Based on the survey data, we also construct a "durable trade frequency" proxy as the sum of the $0 / 1$ dummies for the three entries Jewelry \& Antiques, Cars.., Furniture \& appliances.. (we exclude housing because there are few observations available in a given year). The proxy variable ranges from 0 (no purchases or sales across categories) to 4 (at least one purchase and one sale in each category). Figure 7 shows that the asset trade frequency and this proxy for durable purchase frequency are strongly correlated. Table 11 shows that the bivariate correlation remains strong and statistically significant in a multivariate regression analysis that includes household income and demographics. The correlation is also visible if the sample is restricted to the equity investors (those for whom according to the model the information problem is likely to be more relevant).

\footnotetext{
${ }^{27}$ The same pattern is found by running logit regressions for the purchase of durables, on trade frequencies dummies, non-durables consumption, and demographics.
} 
Table 11: Durable vs. portfolio trade frequency

\begin{tabular}{|c|c|c|c|c|}
\hline \multicolumn{3}{|c|}{ Dependent variable: (log) durable trade freq. } & Regressor: & folio trade fre \\
\hline & All investo & rs (2,808 obs.) & \multicolumn{2}{|c|}{ Equity investors (1,535 obs.) } \\
\hline \multirow{3}{*}{ Trade freq. (log) } & bivariate $^{a}$ & Multivariate $^{b}$ & bivariate $^{a}$ & Multivariate $^{b}$ \\
\hline & 0.27 & 0.16 & 0.16 & 0.09 \\
\hline & $(0.03)$ & $(0.03)$ & $(0.04)$ & $(0.04)$ \\
\hline
\end{tabular}

\section{Conclusions}

This paper provides a quantitative analysis of the rational inattention hypothesis by studying how investors manage their financial assets, liquidity and consumption under the assumption that they face a cost to observe the value of their assets. First, we present direct empirical evidence from a cross-section of individual investors that is consistent with key features of costly observation models: investors collect information about the value of their investments and trade in assets only infrequently. To the best of our knowledge, this is the first direct evidence that is brought to bear on the issue of infrequent portfolio observations/trades and costly observation of the relevant state.

The second contribution is to modify one single feature of existing rational inattention models of asset management in a way that allows the theory to get closer to matching the data. The modification consists in shifting the focus from non-durable to durable consumption choices. As discussed in the introduction, state-of-the art models based on non-durable consumption yield two counterfactual predictions: an equal frequency of observing and trading, and a negative link between the frequency of trading and the investor's liquidity. Our model of durable goods adjustment and asset management reconciles the theory with the data, as the model predicts that the frequency of observing must be greater than the frequency of asset trading, and is consistent with the empirical absence of correlation between liquid assets holdings and assets trading frequency.

Two predictions of the durable-goods model are supported by the data. First, a positive correlation is detected between trades in assets and in durables. Second, the heterogeneity in the frequency investors observe their investments can be explained by heterogeneous risk attitudes: because more risk tolerant individuals invest more in volatile assets they value 
information more and thus gather information more frequently.

A quantitative assessment of the consequences of observation and transaction costs is developed using numerical simulations of the model to match the number of observations and trades of the median Italian investor (about 4 and 0.4 per year, respectively) for a financial wealth of 50,000 euros. The analysis shows that a model with durable goods and no transaction costs implies that to reproduce the low trading frequency observed in the data the observation costs need to be in the order of 100 euros per observation. Considering the narrow notion of information gathering used by our paper, namely observing the value of one's financial wealth, these costs seem unrealistically high. The model with both costs can reproduce the observed frequency of portfolio observations and asset trading with small observation costs (about 10 euro cents per observation) and transaction costs of about 100 euros per trade. Even though these small observation costs help explaining infrequent observations, the model shows they have negligible economic consequences: the patterns of consumer choices and frequency of trades is very close to the one observed if attention costs are absent and consumers only face trading costs. Based on this, we conclude that assets observation costs, and the inattention they induce, have negligible economic consequences. Trading costs of the classical nature emphasized in the literature carry instead first order losses to consumers.

The small value of observation costs that we end up estimating is not inherent to the model we propose, but follows by matching the model with the investors' data. In Alvarez, Lippi, and Paciello (2009) we study the price setting problem of a firm facing both an observation cost and an adjustment (menu) cost. While the context is different the nature of the problem is similar and the firm's frequency of observation and adjustment (i.e. price changes) depend, as in this paper, on the relative costs of each of these actions. Using data on price-reviews and price-changes from a sample of European firms we find that large observation costs and small menu costs are more appropriate to account for the price-review and price-adjustment frequencies, opposite to the investors' data. This is due to a smaller observation frequency (about 2 times per year) and a smaller gap between the frequency of price-review and that of price-adjustment (the ratio of adjustments to observations is about $1 / 2$ ). We see these findings as reasonable: the observation cost for the investor involves a rather simple task, namely checking the value of her portfolio. Instead, the observation cost for firms is plausibly larger, as it involves finding out the value of marginal cost or the demand curve. Also the adjustment cost for firms, the menu cost, is likely small compared with the typically large costs involved in the buying (and selling) of durables.

The analysis in this paper assumes that all observations are costly. In the context of the portfolio and savings model, where several financial shocks are likely correlated across 
agents, households might be able to learn the realization of some shocks without paying the observation cost, a possibility that is not allowed for in our model. In principle, the model might be extended to allow for the random arrival of some free information, along the lines of Alvarez and Lippi (2009). Two remarks are in order. First while the risky portfolio in the model is a single asset, in reality households portfolios are far from perfectly correlated, so that the "observation" activity may be more involved than the mere reading the heading of the news. Second, and more importantly, when we confront the model with simple statistics from the data we find that that the implied observation cost is very small: the model without cost is almost equivalent to that with the calibrated cost. Hence, even without having agents learning some feature of the value of assets exogenously and without cost we find that the data, as interpreted by our model, points to already extremely small observation cost.

We think that several variations and extensions of the model are worth exploring next. In particular, our model assumes that assets are the only income source for the investor and that all consumption is in the form of durable goods. While our empirical analysis concentrated on a sample of investors, assets are not the only income source for these households. ${ }^{28}$ Adding non-durable consumption should be interesting too, partly because it accounts for a large part of total expenditures, and partly because it is complementary to the use of liquid assets. We think that fully incorporating labor income and non-durable consumption is interesting to broaden the applicability of the analysis, but it involves several challenges. Some are conceptual, such as the modeling the observation of one's labor income process, others are technical, such as the proliferation of states in the problem, and finally other challenges are empirical, such as locating relevant data sets for the measurement of observation frequencies and the action that it triggers related to labor income and non-durable consumption. ${ }^{29}$

On the theoretical side, we also find it interesting to study how the decisions rules of models that combine both state dependent and time dependent type of adjustments aggregate and how these type of rules affect the response to aggregate shocks. We leave these tasks for future research.

\footnotetext{
${ }^{28}$ That is why we also included data on the share of labor income as control in the empirical analysis.

${ }^{29}$ See Sims (2003), Reis (2006a) for a model of information gathering about the properties of labor income and the adjustment of non-durable consumption.
} 


\section{References}

Abel, Andrew B., Janice C. Eberly, and Stavros Panageas. 2007. "Optimal Inattention to the Stock Market." American Economic Review 97 (2):244-249.

- 2009. "Optimal Inattention to the Stock Market with Information Costs and Transactions Costs." Mimeo - The Wharton School of the University of Pennsilvania.

Alvarez, Fernando, Andrew Atkeson, and Chris Edmond. 2003. "On the Sluggish Response of Prices to Money in an Inventory-Theoretic Model of Money Demand." Working Paper 10016, National Bureau of Economic Research.

Alvarez, Fernando E. and Francesco Lippi. 2009. "Financial Innovation and the Transactions Demand for Cash." Econometrica 77 (2):363-402.

Alvarez, Fernando E., Francesco Lippi, and Luigi Paciello. 2009. "Optimal price setting with observation and menu costs." Mimeo - EIEF.

Attanasio, Orazio, Luigi Guiso, and Tullio Jappelli. 2002. "The Demand for Money, Financial Innovation and the Welfare Cost of Inflation: An Analysis with Household Data." Journal of Political Economy 110 (2):318-351.

Barsky, Robert B., Thomas F. Juster, Miles S. Kimball, and Matthew D. Shapiro. 1997. "Preference Parameters and Behavioral Heterogeneity: An Experimental Approach in the Health and Retirement Study." The Quarterly Journal of Economics 112 (2):537-79.

Bonaparte, Yosef and Russell Cooper. 2009. "Costly Portfolio Adjustment." NBER Working Papers 15227, National Bureau of Economic Research, Inc. URL http://ideas.repec.org/p/nbr/nberwo/15227.html.

Brandolini, Andrea and Luigi Cannari. 1994. "Methodological Appendix: The Bank of Italy Survey of Household Income and Wealth." in Albert Ando, Luigi Guiso, and Ignazio Visco, (eds.) Saving and the accumulation of wealth: Essays on Italian household and government saving behavior, Cambridge University Press.

Duffie, Darrell. 2010. "Asset Price Dynamics with Slow-Moving Capital." AFA Presidential Address, ASSA Meetings Atlanta January 2-6 2010.

Duffie, Darrell and Tong-sheng Sun. 1990. "Transactions costs and portfolio choice in a discrete-continuous-time setting." Journal of Economic Dynamics and Control 14 (1):3551. 
Gabaix, Xavier and David Laibson. 2001. "The 6D Bias and the Equity Premium Puzzle." NBER Macroeconomics Annual 16 (1):257-312.

Grossman, Sanford J. and Guy Laroque. 1990. "Asset pricing and optimal portfolio choice in the presence of illiquid durable consumption goods." Econometrica 58 (1):25-51.

Guiso, Luigi and Tullio Jappelli. 2007. "Information Acquisition and Portfolio Performance." Economics Working Papers ECO2007/45, European University Institute.

Guiso, Luigi and Monica Paiella. 2008. "Risk Aversion, Wealth, and Background Risk." Journal of the European Economic Association 6 (6):1109-1150.

ICI. 2005a. "Appendices: Additional figures for equity ownership in America." Tech. rep., Investment Company Institute and the Security Industry Association. URL www.ici.org.

—. 2005b. "Equity Ownership in America." Tech. rep., Investment Company Institute and the Security Industry Association. URL www.ici.org.

Mankiw, N. Gregory and Ricardo Reis. 2002. "Sticky Information Versus Sticky Prices: A Proposal To Replace The New Keynesian Phillips Curve." The Quarterly Journal of Economics 117 (4):1295-1328.

Peress, Jol. 2004. "Wealth, Information Acquisition, and Portfolio Choice." Review of Financial Studies 17 (3):879-914.

Reis, Ricardo. 2006a. "Inattentive consumers." Journal of Monetary Economics 53 (8):17611800.

. 2006b. "Inattentive producers." Review of Economic Studies 73 (3):793-821.

Sims, Chris A. 2003. "Implications of rational inattention." Journal of Monetary Economics $50(3): 665-690$.

Sims, Christopher A. 2005. "Rational inattention: a research agenda." Discussion Paper Series 1: Economic Studies 2005,34, Deutsche Bundesbank, Research Centre.

Stokey, Nancy L. 2008. Economics of Inaction: Stochastic Control Models with Fixed Costs. Princeton Univ Pr.

. 2009. "Moving Costs, Nondurable Consumption and Portfolio Choice." J. Econ. Theory 144 (6). 
Verrecchia, Robert E. 1982. "Information Acquisition in a Noisy Rational Expectations Economy." Econometrica 50 (6):1415-30.

Woodford, Michael. 2008. "Information Constrained State Dependent Pricing." Mimeo, Columbia University. 


\section{A Data sources and variables' definitions}

\section{A.1 The Survey of Household Income and Wealth (SHIW)}

The Bank of Italy Survey of Household Income and Wealth (SHIW) collects detailed data on demographics, households' consumption, income, transaction habits and money holdings and household financial and real assets. It started to be run in the mid 1960s but is available on tape only since 1984. Since 1989 it has been conducted biannually and sampling methodology, sample size and broad contents of the information collected is unchanged. It is one of the few household surveys that collects consumption information, separately for non durable expenditures and purchases of durable categories, together with wealth and income data. In this study we rely on the 2004 wave which matches closely the 2003 UCS. Each survey covers about 8,000 households, constituting a representative sample of the Italian resident population. Sampling is in two stages, first municipalities and then households. Households are randomly selected from registry office records. Households are defined as groups of individuals related by blood, marriage or adoption and sharing the same dwelling. The head of the household is conventionally identified with the husband, if present. Brandolini and Cannari (1994) present a detailed discussion of sample design, attrition, response rates and other measurement issues, and comparisons of the SHIW variables with the corresponding aggregates. The 2004 wave interviewed 8,012 households with a response rate of $36 \%$. The SHIW is publicly accessible; an English version of the questionnaire is available and data can be downloaded at www.bancaditalia.it/statistiche/indcamp/bilfait.

Figure A-8: Time spent gathering financial information

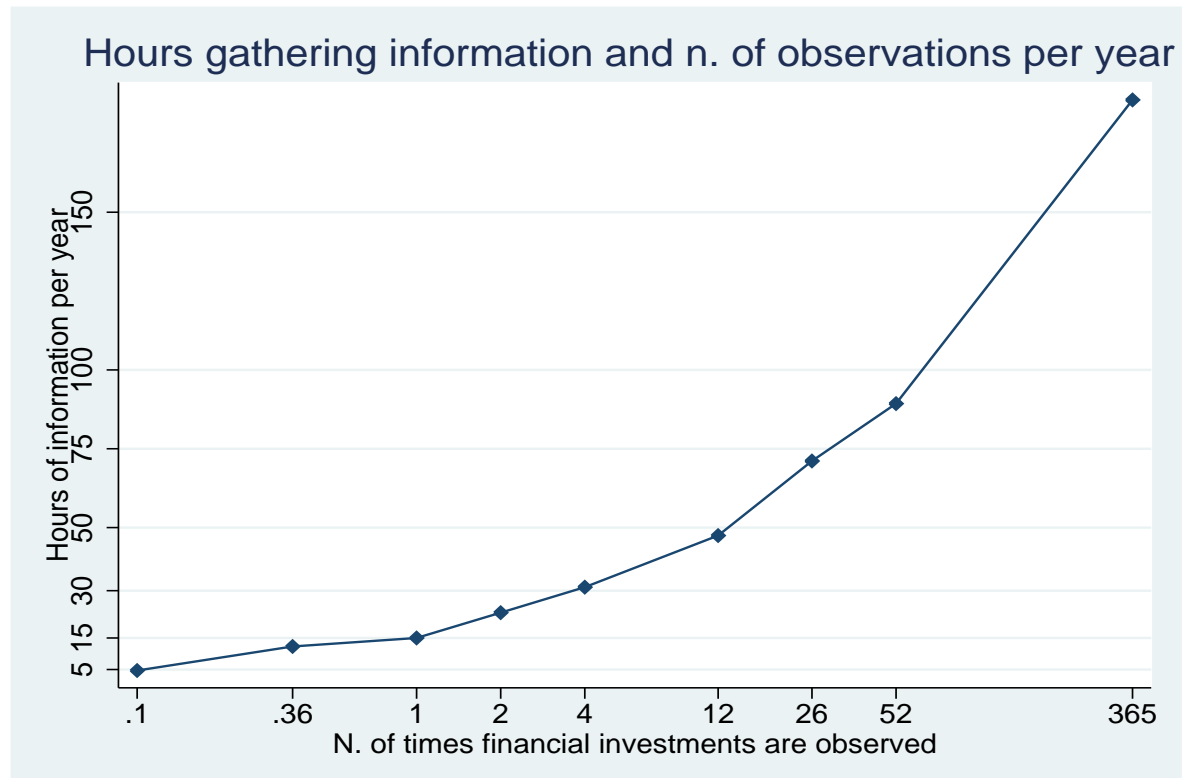

Source: UCS 2003 survey 


\section{A.2 The Unicredit Survey (UCS)}

The Unicredit Investors Survey (UCS) draws on the population of clients of one of the three largest European banking groups, with over 4 million accounts in Italy. Two waves of the survey, which is proprietary, are currently available, the first was run in 2003, the second in 2007. The first wave interviewed 1,834 individuals (1,716 the second) with a checking account in one of the banks that are part of the Unicredit Group based in Italy. The sample is representative of the eligible population of customers, excluding customers less than 20 years old or older than 80, and those who hold accounts of less than 1,000 euro (less than 10,000 euros in the 2007 wave) or more than 2.5 million euro.

UCS goal is to study retail customers' financial behavior and expectations. The survey has detailed information on households' demographic structure, individuals financial assets holding (both within and outside the bank), real wealth components and income. It has data on attitudes towards saving and financial investment, propensity to take financial risk, retirement saving and life insurance as well as data relevant for financial decision taking such as financial information activity, financial literacy, trading experience and practice, assets knowledge and confidence in markets. Interviews for the first wave have been administered between September 2003 and January 2004 ( in the first half of 2007 for the second wave) by an Italian leading poll agency, which also serves the Bank of Italy for the Survey on Household Income and Wealth (SHIW). Most interviewers had substantial experience in administering the Bank of Italy SHIW (see below). The Computer Assisted Personal Interview (CAPI) methodology was employed for all interviews. Before the interview, each customer was contacted by phone.

The sampling design is similar to that of the Bank of Italy SHIW. As in SHIW, the population of account holders is stratified along geographical area of residence (North-East, North-West, Central and Southern Italy), city size (less that 30,000 inhabitants and more), and wealth held with Unicredit (as of December 31, 2003). The use of the same company to run the field and the similar sample design facilitates the comparison between UCS and SHIW. The questionnaire was designed with the help of field experts and academic researchers. It has several sections, dealing with household demographic structure, occupation, propensity to save, to invest and to risk, financial information and literacy, individual and household financial portfolio and investment strategies, real estate, entrepreneurial activities, income and expectations, life insurance and retirement income. The wealth questions match those in the Bank of Italy SHIW, which allows interesting comparison between the wealth distributions in the two surveys.

An important feature of the UCS is that sample selection is based on individual clients of Unicredit. The survey, however, contains detailed information also on the household head - defined as the person responsible for the financial matters of the family - and spouse, if present. Financial variables are elicited for both respondents and household.

\section{A.3 UCS assets data and wealth definition}

UCS contains detailed information on ownership of real and financial assets, and amounts invested. Real assets refer to the household. Financial assets refer to both the account holder and the household. For real assets, UCS reports separate data on primary residence, 
investment real estate, land, business wealth, and debt (mortgage and other debt). Real asset amounts are elicited without use of bracketing.

Two definitions of financial wealth are available. One refers to the individual account holder, and the other to the entire household. The two can differ because some customers keep financial wealth also in different banks or financial institutions (multi-banking) and/or because different household members have different accounts. In this study we only rely on household level variables.

Calculation of financial assets amounts requires some imputation. First of all, respondents report ownership of financial assets grouped in 10 categories. Respondents are then asked to report financial assets amounts; otherwise, they are asked to report amounts in 16 predetermined brackets and if the stated amount is closer to the upper or lower interval within each bracket. In the 2003 wave the questions are the same used in the Bank of Italy SHIW.

\section{A.4 The distribution of financial wealth in the UCS and SHIW survey}

Since the UCS sample only includes banked individuals and there is an asset threshold for participation in the survey, it is no surprise that investors in the two samples are different particularly in terms of average assets holdings. While in the UCS sample people have on average euros 212,000 (median 56,000) in financial assets, the average in SHIW 2004 is only 23,400 (median 7,000 ). To make a more meaningful comparison between the two dataset we select SHIW and UCS households so as to include only those with positive investments other than in transaction accounts but exclude those with financial assets greater than 1 million euros, to try account for the oversampling of the wealthy in UCS.

Figure A-9: Household distribution of wealth in SHIW and UCS

SHIW 2004

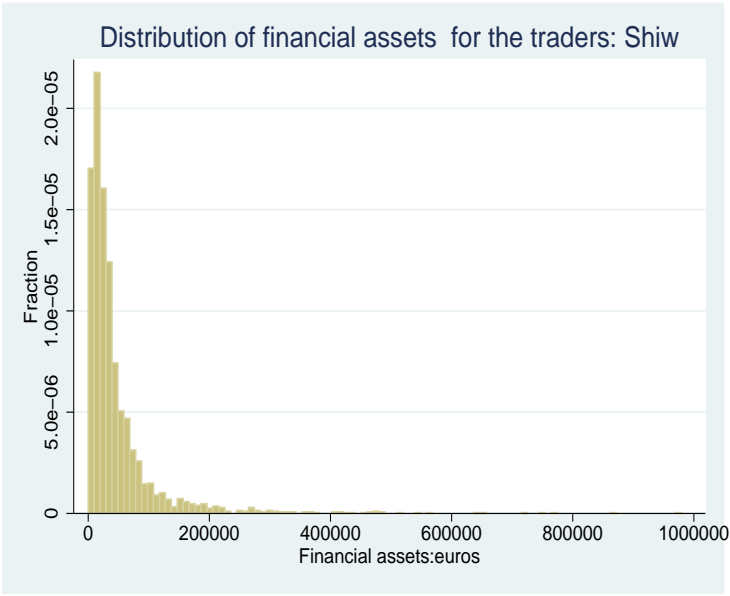

Unicredit 2003

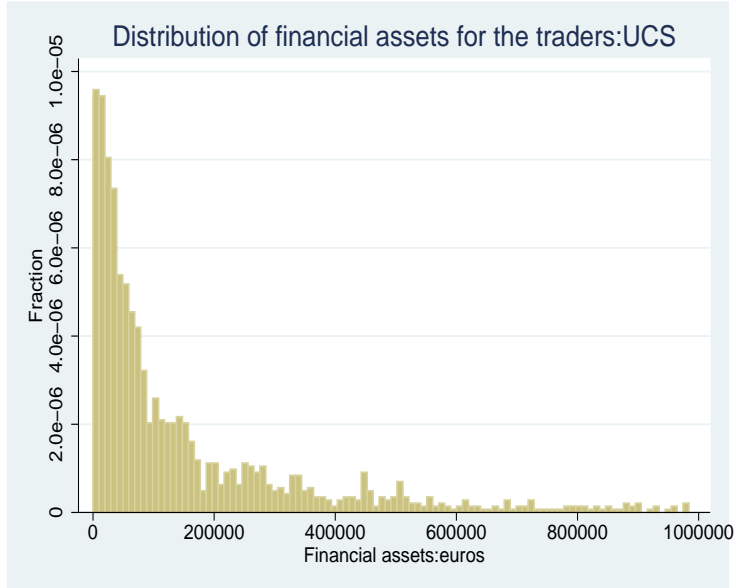

Figure A-9 shows the distribution of financial wealth in the 2003 UCS and the 2004 SHIW; once the comparison is limited to the sample of investors the shapes of the distribution become 
more similar, though large differences between the two dataset remain mainly because UCS is designed to oversample the financially wealthy, as can be seen from the thicker probability mass in the UCS distribution at higher levels of wealth.

\section{A.5 Definition of variables constructed from survey responses}

Attention when buying durables. Response to the question in UCS 2007: "Before making a purchase involving a relatively large amount of money (such as a car, a washing machine or furniture), some people tend to visit several shops or dealers in order to compare various prices and try to get a good balance in terms of price/quality ratio. How does this description fits your type?" Possible answers are: "Not at all", "Very little, "Somewhat.", "Close enough", "Very much". We code these answers with numbers between 1 and 5 .

Cash holdings. Only available in SHIW which asks people: "What sum of money do you usually have in the house to meet normal household needs?"

Number of withdrawals. Only available in SHIW which asks people: "In 2004 how many cash withdrawals did you or other members of your household make directly at a bank or Post Office on average per month?"

Durable consumption purchases. Only available in SHIW which collects information on purchases of three categories of durables: precious objects, means of transport, and furniture, furnishings, household appliances and sundry articles, by asking: "During 2004 did you (or your household) buy ... (item...)? If "Yes, what is the total value of the objects bought (even if they were not paid for completely)?" Thus, SHIW collects separately whether a purchase took place and its value.

Financial diversification. The ratio of stocks held in mutual funds and other investment accounts to total stocks (direct plus indirect). The index ranges from 0 to 1 .

Liquid assets. We use two measures of liquid assets, a narrow one corresponding roughly to M1, and a broader one similar to M2. The first measure is defined as the sum of average cash holdings and checking accounts; the broader measure adds to this savings accounts. Accounts are figures at the household level and figures are variables are defined in the same way in UCS and SHIW. Since UCS has no information on average cash holdings, we impute it from SHIW 2004. Imputation is done by first running a regression on the SHIW sample (retaining only those with a checking account) of average cash holdings (scaled by house value) on a number of variable observed also in UCS: a set of demographics, a fifth order polynomial in income (scaled by house value), a forth order polynomial in age and interactions between demographics and house value and interactions between income and the polynomial in age and income and demographics. The regressions explains $64 \%$ of the cross sectional variability. The estimated coefficients are retrieved and used to predict cash holdings in UCS 2003.

Non durable consumption. From the SHIW question: "What was the monthly average spending of your household in 2004 on all consumer goods, in cash, by means of credit cards, cheques, ATM cards, etc?. Consider all spending, on both food and non-food consumption, and exclude only: purchases of precious objects, purchases of cars, purchases of household appliances and furniture, maintenance payments, extraordinary maintenance of your dwelling, rent for the dwelling, mortgage payments, life insurance premiums, contributions to private pension funds". Answers are multiplied by 12 to obtain an annual figure. Since non durable 
consumption is not available in UCS, it is imputed using SHIW information. This is done by first running a regression on the SHIW sample (retaining only those with a checking account) of non durable consumption (scaled by house value) on a number of variable observed also in UCS: a set of demographics, a fifth order polynomial in income (scaled by house value), a forth order polynomial in age, interactions between demographics and house value and interactions between income and the polynomial in age and income and demographics. The regression explains $91 \%$ of the cross sectional variability. The estimated coefficients are retrieved and used to predict cash holdings in UCS 2003.

Observing frequency. Response to the question: "How frequently do you check the value of your financial investment?" Coded as: every day; at least once a week; about every two weeks; about every month; about every three months; about every six months; about every year; less than once a year; never. The number of times (frequency) an investor observes her investments is computed from the responses as: every day $=365$; at least once a week $=52$; about every two weeks $=26$; about every month $=12$; about every three months $=4$; about every $\operatorname{six}$ months $=2$; about every year $=1$; less than once a year $=0.36$; never $=0.10$. To impute the last category we approximate "never" as meaning once every 10 years.

Stockholders. We construct two identifiers of stockholders: direct and total. Direct stockholders are investors owing stocks of single companies, either listed or unlisted. Total stockholders own stocks either directly or through a mutual fund or a managed investment account.

Risk aversion. Response to the question in UCS: "Which of the following statements comes closest to the amount of financial risk that you are willing to take when you make your financial investment?: (1) a very high return, with a very high risk of loosing the money; (2) high return and high risk; (3) moderate return and moderate risk; (4) low return and no risk."

Time spent in collecting financial information. Response to question: "How much time do you usually spend, in a week, to acquire information on how to invest your savings? (think about time reading newspapers, internet, talk to your financial advisor, etc.)". Coded as: no time; less than 30 minutes; between 30 minutes and 1 hour; 1-2 hours; 2-4 hours; 4-7 hours; more than 7 hours. The hours per year indicator is constructed by coding: no time=0; less than 30 minutes $=0.25 \times 4 \times 12=12$ (assuming 15 minutes a week); between 30 minutes and 1 hour $=(45 / 60) \times 4 \times 12=36$ (assuming 45 minutes a week; $1-2$ hours $=(90 / 60) \times 4 \times 12=72$ (assuming 90 minutes a week); $2-4$ hours $=(180 / 60) \times 4 \times 12=144$ (assuming 3 hours a weak); $4-7$ hours $=(330 / 60) \times 4 \times 12=264$ (assuming 5 hours and 30 minuets a weak); more than 7 hours $(450 / 60) \times 4 \times 12=360$ (assuming 7 hours and 30 minutes a weak).

Trading. Response to question: "How often do you trade financial assets (sell or buy financial assets)?" Coded as: every day; at least once a week; about every two weeks; about every month; about every three months; about every six months; about every year; less than once a year; at maturity; never. The number of times (frequency) an investor trades her investments is computed from the responses as: every day $=365$; at least once a week $=52$; about every two weeks $=26$; about every $\operatorname{month}=12$; about every three months $=4$; about every six months $=2$; about every year $=1$; less than once a year $=0.36$; at maturity $=0.25$; never $=0.10$. To impute the last two categories we assume that average maturity is 4 years and approximate "never" to mean once every 10 years. 
Online Appendices

Durable consumption and asset management with transactions and observation costs

Fernando Alvarez (U. Chicago)

Luigi Guiso (EUI)

Francesco Lippi (U. Sassari) 


\section{AA - 2 Special cases}

This appendix outlines special cases of the more general problem with both information and transactions costs described in the text.

\section{AA - 2.1 The frictionless case: $\phi_{o}=\phi_{T}=0$}

The first order conditions for the continuous time problem are:

$$
\begin{aligned}
\theta: & 0=U^{\prime}(\theta w) w+v^{\prime}(w)[-\delta-\alpha \mu-(1-\alpha) r] w-v^{\prime \prime}(w)(1-\theta) \alpha^{2} \sigma^{2} w^{2} \\
\alpha & : \quad 0=v^{\prime}(w)[(1-\theta)(\mu-r)] w+\left[v^{\prime \prime}(w)(1-\theta)^{2} \sigma^{2} w^{2}\right] \alpha .
\end{aligned}
$$

We can rewrite the foc's as:

$$
\begin{aligned}
\theta & : \quad \frac{U^{\prime}(\theta w)}{v^{\prime}(w)}+\frac{-v^{\prime \prime}(w) w}{v^{\prime}(w)}(1-\theta) \alpha^{2} \sigma^{2}=\delta+r+\alpha(\mu-r), \\
\alpha & : \quad(1-\theta) \alpha=\frac{1}{-v^{\prime \prime}(w) w / v^{\prime}(w)}\left[\frac{\mu-r}{\sigma^{2}}\right] .
\end{aligned}
$$

We assume that the utility function is homogenous of degree $\gamma>0, U(d)=\frac{d^{1-\gamma}}{1-\gamma}$. In this case the value function will be homogenous of degree $\gamma$ too, so we can write it as:

$$
v(w)=v(1) w^{1-\gamma}
$$

and foc becomes:

$$
\begin{aligned}
\theta: & \frac{\theta^{-\gamma}}{(1-\gamma) v(1)}+\gamma(1-\theta) \alpha^{2} \sigma^{2}=\delta+r+\alpha(\mu-r) \\
\alpha & : \quad \alpha(1-\theta)=\frac{1}{\gamma} \frac{\mu-r}{\sigma^{2}}
\end{aligned}
$$

and the Bellman equation

$$
\rho v(1)=\frac{\theta^{1-\gamma}}{1-\gamma}+v(1)(1-\gamma)\left[-\theta \delta+(1-\theta)(r+\alpha(\mu-r))-\frac{1}{2} \gamma \sigma^{2} \alpha^{2}(1-\theta)^{2}\right]
$$

The foc w.r.t. $\theta$ and the Bellman equation can be combined and simplify to:

$$
\begin{aligned}
& \frac{\theta^{1-\gamma}}{v(1)(1-\gamma)}=-\gamma(1-\theta) \theta \alpha^{2} \sigma^{2}+\theta(\delta+r+\alpha(\mu-r)) \\
& \frac{\theta^{1-\gamma}}{v(1)(1-\gamma)}=\rho-(1-\gamma)\left(-\theta \delta+(1-\theta)(r+\alpha(\mu-r))-\frac{1}{2} \gamma \sigma^{2}(1-\theta)^{2} \alpha^{2}\right) .
\end{aligned}
$$


Equating these two expressions we obtain:

$$
\begin{aligned}
& -\gamma(1-\theta) \theta \alpha^{2} \sigma^{2}+\theta[\delta+r+\alpha(\mu-r)] \\
= & \rho-(1-\gamma)\left[-\theta \delta+(1-\theta)(r+\alpha(\mu-r))-\frac{1}{2} \gamma \sigma^{2}(1-\theta)^{2} \alpha^{2}\right] .
\end{aligned}
$$

We are looking for a solution for this equation with $\theta>0$. This will require some assumptions on parameters. Among these assumptions, we will include conditions that guarantee that the problem has a finite solution. We will consider two cases. In the first case $\alpha$ is exogenous, and the second where $\alpha$ is optimized over. In the first case this expression is quadratic equation in $\theta$. In the second case, where we replace $\alpha$ by its solution found above, $\theta$ can be written as the zero of a higher order polynomial.

In the case of $\alpha$ endogenous, substituting the first order conditions for $\alpha(1-\theta)=(\mu-$ $r) /\left(\sigma^{2} \gamma\right)$ we obtain:

$$
\theta=\frac{1}{\gamma} \frac{\rho}{(\delta+r)}-\frac{1-\gamma}{\gamma} \frac{\left[r+\frac{1}{2}(\mu-r)^{2} /\left(\gamma \sigma^{2}\right)\right]}{\delta+r}
$$

Few comments are in order. First, as $\delta \rightarrow \infty$, then $\theta \rightarrow 0$. Second, for $\gamma=1$, the 'log' case, the expression for $\theta=\rho /(\delta+r)$. When $\gamma>1$ this expression is always positive. When $\gamma<1$, the expression for $\theta$ can be negative. It is non-negative if

$$
\rho \geq(1-\gamma)\left[r+\frac{1}{2}(\mu-r)^{2} /\left(\gamma \sigma^{2}\right)\right] .
$$

This conditions ensures that the discount rate $\rho$ is large enough so that utility is bounded from above.

Coming back to the expression for the value function, replacing the optimal value of $\alpha$ on the foc for $\theta$ derived above we obtain:

$$
v(1)=\frac{\theta^{-\gamma}}{(1-\gamma)(r+\delta)}
$$

thus, as long as $\theta$ as given in (AA-7) is non-negative, which is assured by condition (AA-8), the problem is well defined.

\section{AA - 2.2 The problem with observation cost only}

This appendix derives the first order conditions that solve the problem with observation cost (and no transaction cost).

$$
\begin{aligned}
v(1) & =\frac{1-e^{-(\rho+(1-\gamma) \delta) \tau}}{(1-\gamma)(\rho+(1-\gamma) \delta)} \theta^{1-\gamma} \\
& +e^{-\rho \tau} v(1) \int_{-\infty}^{\infty}\left[(1-\theta)\left(1-\phi_{o}\right) R(s, \tau, \alpha)+\theta e^{-\delta \tau}\right]^{1-\gamma} d N(s)
\end{aligned}
$$

Letting $\Omega \equiv(1-\theta)\left(1-\phi_{o}\right)$ for notation convenience, the foc of $(13)$ with respect to $\tau$ 
gives

$$
\begin{gathered}
\frac{\left(\theta e^{-\delta \tau}\right)^{1-\gamma}}{1-\gamma}=\rho v(1) \int_{-\infty}^{\infty}\left(\Omega R(s, \tau, \alpha)+\theta e^{-\delta \tau}\right)^{1-\gamma} d N(s)+ \\
-v(1) \int_{-\infty}^{\infty}(1-\gamma)\left[\Omega R(s, \tau, \alpha)+\theta e^{-\delta \tau}\right]^{-\gamma}\left[\Omega \frac{\partial R(s, \tau, \alpha)}{\partial \tau}-\delta \theta e^{-\delta \tau}\right] d N(s)
\end{gathered}
$$

where

$$
\frac{\partial R(s, \tau, \alpha)}{\partial \tau}=\left[\alpha \mu+(1-\alpha) r-\alpha^{2} \frac{\sigma^{2}}{2}+\frac{\alpha \sigma s}{2 \sqrt{\tau}}\right] R(s, \tau, \alpha)
$$

Simple algebraic manipulation of (AA-11) yields:

$$
\int_{-\infty}^{\infty}\left\{\frac{\Omega\left(\rho R(s, \tau, \alpha)-(1-\gamma) \frac{\partial R(s, \tau, \alpha)}{\partial \tau}\right)+\theta e^{-\delta \tau}(\rho+(1-\gamma) \delta)}{\left[\Omega R(s, \tau, \alpha)+\theta e^{-\delta \tau}\right]^{\gamma}}\right\} d N(s)=\frac{\left(\theta e^{-\delta \tau}\right)^{1-\gamma}}{(1-\gamma) v(1)}
$$

The foc with respect to $\theta$ gives:

$$
\frac{1-e^{-(\rho+(1-\gamma) \delta) \tau}}{v(1)(\rho+(1-\gamma) \delta) e^{-\rho \tau}(1-\gamma)} \theta^{-\gamma}=\int_{-\infty}^{\infty} \frac{\left(1-\phi_{o}\right) R(s, \tau, \alpha)-e^{-\delta \tau}}{\left[(1-\theta)\left(1-\phi_{o}\right) R(s, \tau, \alpha)+\theta e^{-\delta \tau}\right]^{\gamma}} d N(s)
$$

Rewrite eq (AA-10) as

$\frac{1-e^{-(\rho+(1-\gamma) \delta) \tau}}{v(1)(\rho+(1-\gamma) \delta) e^{-\rho \tau}(1-\gamma)} \theta^{-\gamma}=\frac{e^{\rho \tau}}{\theta}-\frac{1}{\theta} \int_{-\infty}^{\infty}\left[(1-\theta)\left(1-\phi_{o}\right) R(s, \tau, \alpha)+\theta e^{-\delta \tau}\right]^{1-\gamma} d N(s)$

Equating these two equations gives

$$
e^{\rho \tau}=\int_{-\infty}^{\infty} \frac{\left(1-\phi_{o}\right) R(s, \tau, \alpha)}{\left[(1-\theta)\left(1-\phi_{o}\right) R(s, \tau, \alpha)+\theta e^{-\delta \tau}\right]^{\gamma}} d N(s)
$$

The foc with respect to $\alpha$ gives

$$
0=\int_{-\infty}^{\infty} \frac{\frac{\partial R(s, \tau, \alpha)}{\partial \alpha}}{\left[(1-\theta)\left(1-\phi_{o}\right) R(s, \tau, \alpha)+\theta e^{-\delta \tau}\right]^{\gamma}} d N(s)
$$

where

$$
\frac{\partial R(s, \tau, \alpha)}{\partial \alpha}=\left[\left(\mu-r-\alpha \sigma^{2}\right) \tau+\sigma s \sqrt{\tau}\right] R(s, \tau, \alpha)
$$

Equations (AA-10), (AA-12), (AA-14) and (AA-15) give a system of four equations in the 4 unknowns $v(1), \theta, \tau$ and $\alpha$.

\section{AA - 2.3 The Grossman - Laroque case: $\phi_{o}=0$ and $\phi_{T}>0$}

In this appendix we provide more details on the model of Section 4.3 with adjustment cost only. One difference compared to the original GL model is that the portfolio share $\alpha$ can 
only be adjusted when the stock of durables is revised (so $\alpha$ becomes a state for the problem, which we omit for notation simplicity). The value function is:

$$
\rho V(a, d) \geq \frac{d^{1-\gamma}}{1-\gamma}+V_{a}(a, d) a[r+\alpha(\mu-r)]-V_{d}(a, d) d \delta+\frac{1}{2} V_{a a}(a, d) a^{2} \alpha^{2} \sigma^{2}
$$

with equality in the inaction region. The possibility of adjustment gives

$$
V(a, d) \geq \max _{a^{\prime} \geq 0, \alpha} V\left(a^{\prime}, d\left(1-\phi_{T}\right)+a-a^{\prime}\right)
$$

with equality if adjustment of durables is optimal at that $(a, d)$. The maximization with respect to the post-adjustment value of $a^{\prime}$ gives the foc:

$$
V_{a}\left(a^{\prime}, d\left(1-\phi_{T}\right)+a-a^{\prime}\right)=V_{d}\left(a^{\prime}, d\left(1-\phi_{T}\right)+a-a^{\prime}\right) .
$$

The maximization w.r.t. $\alpha$ gives:

$$
\alpha=\frac{\mu-r}{\frac{-V_{a a}(a, d) a}{V_{a}(a, d)} \sigma^{2}} .
$$

We can write all the conditions jointly as:

$$
\begin{aligned}
\rho V(a, d)=\max \quad & \left(\rho \max _{a^{\prime} \geq 0, \alpha} V\left(a^{\prime}, d\left(1-\phi_{T}\right)+a-a^{\prime}\right),\right. \\
& \left.\frac{d^{1-\gamma}}{1-\gamma}+V_{a}(a, d) a[r+\alpha(\mu-r)]-V_{d}(a, d) d \delta+\frac{1}{2} V_{a a}(a, d) a^{2} \alpha^{2} \sigma^{2}\right)
\end{aligned}
$$

Using the homogeneity of $V$, and $x=a / d$, rewrite this equation in the inaction region as

$$
\rho V(x, 1)=\frac{1}{1-\gamma}+V_{a}(x, 1) x[r+\alpha(\mu-r)]-V_{d}(x, 1) \delta+\frac{1}{2} V_{a a}(x, 1) x^{2} \alpha^{2} \sigma^{2}
$$

To write this PDE as an ODE, we use homogeneity to express $V_{d}$ in terms of $V_{a}$,

$$
V_{d}(x, 1)=(1-\gamma) V(x, 1)-x V_{a}(x, 1)
$$

so that, after replacing into the PDE and collecting terms, gives the following ODE:

$$
(\rho+\delta(1-\gamma)) V(x, 1)=\frac{1}{1-\gamma}+V_{a}(x, 1) x[\delta+r+\alpha(\mu-r)]+\frac{1}{2} V_{a a}(x, 1) x^{2} \alpha^{2} \sigma^{2}
$$

so that the solution for $V(x, 1)$ in the inaction range is

$$
V(x, 1)=\frac{1}{(1-\gamma)(\rho+\delta(1-\gamma))}+\sum_{i=1}^{2} A_{i} x^{\eta_{i}}
$$


where the roots $\eta_{i}$ solve the characteristic equation

$$
0=\rho+\delta(1-\gamma)-\left(\delta+r+\alpha(\mu-r)-\frac{\alpha^{2} \sigma^{2}}{2}\right) \eta-\frac{\alpha^{2} \sigma^{2}}{2} \eta^{2} .
$$

The policy rule is characterized by three numbers: the optimal return point $\hat{x}$, and the 2 barriers $(\underline{x}, \bar{x})$ that delimit the inaction region: an agent with $x \in(\bar{x}, \underline{x})$ does not adjust. Outside this region, i.e. for $x \geq \bar{x}$ or $x \leq \underline{x}$, the value function is characterized by paying the fixed cost and adjusting so that the post-adjustment ratio is $\hat{x}$.

The closed form solution for the ODE, up to the two constant of integration $A_{1}, A_{2}$ in the inaction region allows us to then write a system of 5 equations and unknowns. The unknowns are $A_{1}, A_{2}, \underline{x}, \bar{x}, \hat{x}$. The five equations are the first order condition for the optimal return point equation (AA-17), a pair of value matching conditions at each boundary equations (AA-18), and a pair of smooth pasting conditions at each boundary equations (AA-19):

$$
\begin{aligned}
& V_{a}(\hat{x}, 1)=V_{d}(\hat{x}, 1), \\
& \left(\frac{1+\bar{x}-\phi_{T}}{1+\hat{x}}\right)^{1-\gamma} V(\hat{x}, 1)=V(\bar{x}, 1),\left(\frac{1+\underline{x}-\phi_{T}}{1+\hat{x}}\right)^{1-\gamma} V(\hat{x}, 1)=V(\underline{x}, 1), \\
& V_{a}(\underline{x}, 1)\left(1-\phi_{T}\right)=V_{d}(\underline{x}, 1), V_{a}(\bar{x}, 1)\left(1-\phi_{T}\right)=V_{d}(\bar{x}, 1) .
\end{aligned}
$$

Equation (AA-17) follows from equation (AA-16). The value matching equations (AA-18) use that

$$
\begin{aligned}
& V\left(\bar{a}-\tilde{\Delta}^{*}, \bar{d}\left(1-\phi_{T}\right)+\tilde{\Delta}^{*}\right)=\max _{\tilde{\Delta}} V\left(\bar{a}-\tilde{\Delta}, \bar{d}\left(1-\phi_{T}\right)+\tilde{\Delta}\right)=V(\bar{a}, \bar{d}) \\
& 1=\frac{V_{a}(\hat{a}, \hat{d})}{V_{d}(\hat{a}, \hat{d})} \text { and } \frac{\bar{a}-\tilde{\Delta}^{*}}{\bar{d}\left(1-\phi_{T}\right)+\tilde{\Delta}^{*}}=\frac{\hat{a}}{\hat{d}} \Longrightarrow \Delta^{*}=\frac{\bar{x}-\hat{x}\left(1-\phi_{T}\right)}{1+\hat{x}}
\end{aligned}
$$

where $\bar{x}=\bar{a} / \bar{d}, \hat{x}=\hat{a} / \hat{d}$ and $\Delta^{*}=\tilde{\Delta}^{*} / \bar{d}$, and the homogeneity of degree $(1-\gamma)$ of $V(\cdot)$. The same derivation applies in the lower boundary $\underline{x}$. To derive the smooth pasting conditions equations (AA-19) consider pairs $(a, d)$ such that $a+d\left(1-\phi_{T}\right) d=\bar{a}+\bar{d}\left(1-\phi_{T}\right)=\hat{a}+\hat{d}$ and that $a / d>\bar{a} / \bar{d}$ for some fixed $\bar{a}, \bar{d}$ so that after adjustment the agent will go to $\hat{a}, \hat{d}$. Notice that for any such pair $(a, d)$ the agent will also pay the fixed cost and adjust to the same level $\hat{a}, \hat{d}$. Thus we have:

$$
V(a, d)=V(\bar{a}, \bar{d})=V(\hat{a}, \hat{d})
$$

or using $a=\bar{a}+\bar{d}\left(1-\phi_{T}\right)-d\left(1-\phi_{T}\right)$ :

$$
V\left(\bar{a}+\bar{d}\left(1-\phi_{T}\right)-d\left(1-\phi_{T}\right), d\right)=V(\hat{a}, \hat{d})
$$

and differentiating w.r.t. $d$ we have

$$
0=-V_{a}\left(\bar{a}+\bar{d}\left(1-\phi_{T}\right)-d\left(1-\phi_{T}\right), d\right)\left(1-\phi_{T}\right)+V_{d}\left(\bar{a}+\bar{d}\left(1-\phi_{T}\right)-d\left(1-\phi_{T}\right), d\right)
$$


Taking the limit as $d \uparrow \bar{d}$ we have

$$
V_{a}(\bar{a}, \bar{d})\left(1-\phi_{T}\right)=V_{d}(\bar{a}, \bar{d})
$$

and using homogeneity we obtain equation (AA-19). Repeating the same argument for values of $a / d<\underline{a} / \underline{d}$ we obtain the other smooth pasting condition.

For completeness we also describe the expected number of adjustment per unit of time, given the two barriers $\bar{x}$ and $\underline{x}$ and given the optimal return point $\hat{x}$. Let $T(a, d)$ be the expected time until an adjustment takes place, starting from state $(a, d)$. We have

$$
0=1+T_{a}(a, d) a(r+\alpha(\mu-r))-T_{d}(a, d) d \delta+\frac{1}{2} T_{a a}(a, d) a^{2} \alpha^{2} \sigma^{2}
$$

with boundaries $T(\bar{a}, \bar{d})=T(\underline{a}, \underline{d})=0$. We are interested in $T(\hat{a}, \hat{d})$, which gives the expected time between successive adjustments. We notice that $T$ is homogeneous of degree zero, and hence we can write:

$$
0=1+T_{a}(x, 1) x(r+\alpha(\mu-r)+\delta)+\frac{1}{2} T_{a a}(x, 1) x^{2} \alpha^{2} \sigma^{2}
$$

with boundaries $T(\bar{x}, 1)=T(\underline{x}, 1)=0$. The solution to this equation is

$$
T(x)=B_{0}+B_{1} x^{\lambda}+B_{2} \log x
$$

where

$$
\lambda=1-\frac{r+\alpha(\mu-r)+\delta}{\alpha^{2} \sigma^{2} / 2} \quad, \quad B_{2}=\frac{1}{\alpha^{2} \sigma^{2} / 2-(r+\alpha(\mu-r)+\delta)} .
$$

The constants $B_{0}$ and $B_{1}$ are chosen to satisfy the terminal conditions, namely

$$
0=B_{0}+B_{1} \underline{x}^{\lambda}+B_{2} \log \underline{x} \quad, \quad 0=B_{0}+B_{1} \bar{x}^{\lambda}+B_{2} \log \bar{x}
$$

or

$$
B_{0}=-B_{2}\left[\frac{\log \bar{x}-\log \underline{x}}{\underline{x}^{\lambda}-\bar{x}^{\lambda}} \bar{x}^{\lambda}+\log \bar{x}\right] \quad, \quad B_{1}=B_{2} \frac{\log \bar{x}-\log \underline{x}}{\underline{x}^{\lambda}-\bar{x}^{\lambda}}
$$




\section{AA - 2.4 The Bellman equation when $\phi_{o}>0, \phi_{T}>0$}

Here we use the homogeneity of the value function $V(a, d)$ to reduce the Bellman equation to a function of a single variable by setting $d=1$.

$$
\begin{aligned}
& \bar{V}(a, 1, \alpha)=\max _{\tau}\left\{\int_{0}^{\tau} e^{-\rho t} U\left(e^{-t \delta}\right) d t\right. \\
& \left.+\quad e^{-(\rho+(1-\gamma) \delta) \tau} \int_{-\infty}^{\infty} V\left(\left(1-\phi_{o}\right) e^{\delta \tau} R(s, \tau, \alpha) a, 1, \hat{\alpha}\right) d N(s)\right\} \\
& =\max _{\tau}\left\{\frac{1-e^{-(\rho+(1-\gamma) \delta) \tau}}{(1-\gamma)(\rho+(1-\gamma) \delta)}\right. \\
& \left.+e^{-(\rho+(1-\gamma) \delta) \tau} \int_{-\infty}^{\infty} V\left(\left(1-\phi_{o}\right) e^{\delta \tau} R(s, \tau, \alpha) a, 1, \hat{\alpha}\right) d N(s)\right\} \\
& \hat{V}(a, 1)=\max _{\tau, \alpha, 0 \leq a^{\prime} \leq a+1-\phi_{T}}\left\{\int_{0}^{\tau} e^{-\rho t} U\left(\left[a+\left(1-\phi_{T}\right)-a^{\prime}\right] e^{-t \delta}\right) d t\right. \\
& \left.+e^{-\rho \tau} \int_{-\infty}^{\infty} V\left(a^{\prime}\left(1-\phi_{o}\right) R(s, \tau, \alpha),\left[a+\left(1-\phi_{T}\right)-a^{\prime}\right] e^{-\delta \tau}, \hat{\alpha}\right) d N(s)\right\} \\
& =\max _{\tau, \alpha, 0 \leq a^{\prime} \leq a+1-\phi_{T}}\left[a+\left(1-\phi_{T}\right)-a^{\prime}\right]^{1-\gamma}\left\{\int_{0}^{\tau} e^{-\rho t} U\left(e^{-t \delta}\right) d t\right. \\
& \left.+e^{-(\rho+(1-\gamma) \delta) \tau} \int_{-\infty}^{\infty} V\left(\frac{a^{\prime}}{\left[a+\left(1-\phi_{T}\right)-a^{\prime}\right]}\left(1-\phi_{o}\right) e^{\delta \tau} R(s, \tau, \alpha), 1, \hat{\alpha}\right) d N(s)\right\} \\
& =\max _{\tau, 0 \leq a^{\prime} \leq a+1-\phi_{T}}\left[a+\left(1-\phi_{T}\right)-a^{\prime}\right]^{1-\gamma}\left\{\frac{1-e^{-(\rho+(1-\gamma) \delta) \tau}}{(1-\gamma)(\rho+(1-\gamma) \delta)}\right. \\
& \left.+e^{-(\rho+(1-\gamma) \delta) \tau} \max _{\alpha} \int_{-\infty}^{\infty} V\left(\frac{a^{\prime}}{\left[a+\left(1-\phi_{T}\right)-a^{\prime}\right]}\left(1-\phi_{o}\right) e^{\delta \tau} R(s, \tau, \alpha), 1, \hat{\alpha}\right) d N(s)\right\}
\end{aligned}
$$

With these expressions it is easy to see that inaction is optimal around the optimal return point. Consider the feasible policy $a^{\prime}=a$, we have that

$$
\begin{aligned}
\hat{V}(a, 1) & =\max _{\tau, \alpha}\left\{\int_{0}^{\tau} e^{-\rho t} U\left(\left(1-\phi_{T}\right) e^{-t \delta}\right) d t\right. \\
& \left.+e^{-(\rho+(1-\gamma) \delta) \tau} \int_{-\infty}^{\infty} V\left(a e^{\delta \tau} R(s, \tau, \alpha),\left(1-\phi_{T}\right), \hat{\alpha}\right) d N(s)\right\}<\bar{V}(a, 1, \hat{\alpha})
\end{aligned}
$$

where the last inequality follows by the fact that utility is increasing in the stock of durables.

\section{AA - 3 No trade between observations}

Notice that between observation dates, with $\sigma>0$, the agent does not know her wealth. Moreover, there is a strictly positive probability that her wealth can be arbitrarily close to zero. This precludes the strategy where the agent increases her holding of durables between 
observations dates by withdrawing resources from her financial assets, since she may otherwise violate her budget constraint. Thus, we will only need to consider the case where the agent is allowed to decrease her durable holding, and increase her holding for financial assets in between observation dates. We will like to show that it is not optimal to decrease durable goods, and hence that the restriction on the policies is not binding. But to verify this in the case for $\sigma>0$ is complicated, so we restrict attention to the case with $\sigma=0$. We conjecture that the conclusion extends to the case of $\sigma>0$.

In particular for $\sigma=0$ we consider the following variational problem taking as given the interval $\tau$, as well as the initial and final wealth $w(0), w(\tau)$, and where during the observation period the agent can sell durables at rate $x(t)$ and invest the proceeds in the financial assets which accumulate at rate $r$ :

$$
\max _{\{a(0), d(0), a(\tau), d(\tau), x(t)\}} \int_{0}^{\tau} u(d(t)) e^{-\rho t} d t
$$

subject to :

$$
\begin{gathered}
w(0)=a(0)+d(0), w(\tau)=a(\tau)\left(1-\phi_{o}\right)+d(\tau), \\
\dot{d}(t)=-\delta d(t)-x(t), \dot{a}(t)=r a(t)+x(t), \\
a(0), d(0), a(\tau), d(\tau), x(t) \geq 0 .
\end{gathered}
$$

Proposition 1. If $\rho<r+\delta \gamma$, then the non-negativity constraint binds, and the optimal policy is $x(t)=0$ for all $t \in[0, \tau]$.

Notice from equation (11) that in the case of $\phi_{o}=0$ and $\sigma=0$ (so $\mu=r$ ), the solution of the continuous time problem gives a value for the fraction of wealth in durables $\theta$ equal to $\theta=\frac{r-(r-\rho) / \gamma}{r+\delta}$. Thus the condition for $x(t)=0$ given in the proposition is equivalent to the condition for $\theta<1$. This is quite intuitive, for $x(t)=0$ we require the return on the financial portfolio to be good relative to the discount rate and the depreciation rate. Moreover, if the parameters are such that $\theta<1$, then when $\phi_{o}$ is small but positive, the agent will still choose $x(t)=0$.

Proof. Let $e^{-\rho t} \lambda(t)$ be the multiplier of the law of motion of $a$ at $t, e^{-\rho t} \mu(t)$ the multiplier of the law of motion of $d$ at $t, \nu_{0}$ the multiplier of the wealth at $t=0$ constraint, and $\nu_{1}$ the multiplier of the wealth constraint at $t=\tau$. The Lagrangean is:

$$
\begin{aligned}
& \int_{0}^{\tau} e^{-\rho t}[u(d(t))+\lambda(t)(a(t) r+x(t)-\dot{a}(t))+\mu(t)(-d(t) \delta-x(t)-\dot{d}(t))] d t \\
+\quad & \nu_{1}[(1-\phi) a(\tau)+d(\tau)-w(\tau)]+\nu_{0}[w(0)-a(0)-d(0)]
\end{aligned}
$$

Integrating by parts we have:

$$
\begin{aligned}
& \int_{0}^{\tau} e^{-\rho t}[u(d(t))+\lambda(t)(a(t) r+x(t)-\rho a(t))+\dot{\lambda}(t) a(t)+\mu(t)(-d(t) \delta-x(t)-\rho d(t))+\dot{\mu}(t) d(t)] d t \\
& +\nu_{1}[(1-\phi) a(\tau)+d(\tau)-w(\tau)]+\nu_{0}[w(0)-a(0)-d(0)] \\
& -\lambda(\tau) e^{-\rho \tau} a(\tau)+\lambda(0) a(0)-\mu(\tau) e^{-\rho \tau} d(\tau)+\mu(0) d(0)
\end{aligned}
$$


We can then use the current value Hamiltonian, with state state $(d, a)$ and control $x$ is:

$$
H(a, d, y)=u(d)+\mu(-\delta d-x)+\lambda(a r+x)
$$

and use $\mu, \lambda$ the costates. The FOC for $t \in(0, \tau)$ include:

$$
H_{x}=0:-\mu(t)+\lambda(t) \leq 0
$$

with equality if $x(t)>0$, and

$$
\begin{aligned}
& \dot{\lambda}=\rho \lambda-H_{a}: \dot{\lambda}(t)=\rho \lambda(t)-\lambda(t) r \\
& \dot{\mu}=\rho \mu-H_{d}: \dot{\mu}(t)=\rho \mu(t)-u^{\prime}(d(t))+\mu(t) \delta
\end{aligned}
$$

While there are more first order conditions involving $a(0), d(0), a(\tau), d(\tau)$ the previous ones suffice for our current purpose. By way of contradiction, assume $x(t)>0$ in an interval between $0<t_{0}$ and $t_{1}<\tau$. Then $\lambda=\mu$ and $\dot{\lambda} / \lambda=\rho-r$ in this interval:

$$
u^{\prime}(d(t))=\lambda(\delta+r)=(\delta+r) \lambda\left(t_{0}\right) e^{(\rho-r) t}
$$

for $t \in\left[t_{0}, t_{1}\right]$. By taking logs and differentiating w.r.t. time, using that $u(d)=d^{1-\gamma} /(1-\gamma)$ we obtain

$$
\frac{\dot{d}(t)}{d(t)}=\frac{r-\rho}{\gamma}
$$

From the law of motion of $d$, if $x \geq 0$ :

$$
\frac{\dot{d}(t)}{d(t)} \leq-\delta
$$

Hence, if

$$
\rho<r+\delta \gamma
$$

we arrive to a contradiction with $x(t)>0$ on $\left[t_{0} t_{1}\right]$. 